OPEN ACCESS

Edited by:

Seung Kew Yoon,

The Catholic University of Korea,

South Korea

Reviewed by:

Claudia Feriotti,

Queen's University Belfast,

United Kingdom

Kyong-Mi Chang,

University of Pennsylvania

United States

*Correspondence:

Carolina Boni

cboni@ao.pr.it

${ }^{\dagger}$ These authors have contributed equally to this work

Specialty section: This article was submitted to Viral Immunology,

a section of the journal

Frontiers in Immunology

Received: 12 November 2019

Accepted: 14 April 2020

Published: 12 May 2020

Citation:

Fisicaro P, Barili V, Rossi M,

Montali I, Vecchi A, Acerbi G, Laccabue D, Zecca A, Penna A, Missale $G$, Ferrari $C$ and Boni $C$ (2020) Pathogenetic Mechanisms of $T$ Cell Dysfunction in Chronic HBV Infection and Related Therapeutic Approaches. Front. Immunol. 11:849. doi: 10.3389/fimmu.2020.00849

\section{Pathogenetic Mechanisms of T Cell Dysfunction in Chronic HBV Infection and Related Therapeutic Approaches}

\author{
Paola Fisicaro ${ }^{1,2 t}$, Valeria Barili ${ }^{1,2+}$, Marzia Rossi ${ }^{1,2}$, Ilaria Montali ${ }^{1}$, Andrea Vecchi', \\ Greta Acerbi',2, Diletta Laccabue ${ }^{1}$, Alessandra Zecca ${ }^{1}$, Amalia Penna ${ }^{1}$, \\ Gabriele Missale ${ }^{1,2}$, Carlo Ferrari ${ }^{1,2}$ and Carolina Boni ${ }^{1 *}$ \\ ${ }^{1}$ Laboratory of Viral Immunopathology, Unit of Infectious Diseases and Hepatology, Azienda Ospedaliero-Universitaria di \\ Parma, Parma, Italy, ${ }^{2}$ Department of Medicine and Surgery, University of Parma, Parma, Italy
}

A great effort of research has been devoted in the last few years to developing new anti-HBV therapies of finite duration that also provide effective sustained control of virus replication and antigen production. Among the potential therapeutic strategies, immune-modulation represents a promising option to cure HBV infection and the adaptive immune response is a rational target for novel therapeutic interventions, in consideration of the key role played by $T$ cells in the control of virus infections. HBVspecific T cells are severely dysfunctional in chronic HBV infection as a result of several inhibitory mechanisms which are simultaneously active within the chronically inflamed liver. Indeed, the liver is a tolerogenic organ harboring different non-parenchymal cell populations which can serve as antigen presenting cells (APC) but are poorly efficient in effector $T$ cell priming, with propensity to induce $T$ cell tolerance rather than $T$ cell activation, because of a poor expression of co-stimulatory molecules, up-regulation of the co-inhibitory ligands PD-L1 and PD-L2 upon IFN stimulation, and production of immune regulatory cytokines, such as IL 10 and TGF- $\beta$. They include resident dendritic cells (DCs), comprising myeloid and plasmacytoid DCs, liver sinusoidal endothelial cells (LSECs), Kupffer cells (KCs), hepatic stellate cells (HSCs) as well as the hepatocytes themselves. Additional regulatory mechanisms which contribute to T cell attrition in the chronically infected liver are the high levels of soluble mediators, such as arginase, indoleamine 2,3-dioxygenase (IDO) and suppressive cytokines, the up-regulation of inhibitory checkpoint receptor/ligand pairs, the expansion of regulatory cells, such as CD4+FOXp3+ Treg cells, myeloid-derived suppressor cells and NK cells. This review will deal with the interactions between immune cells and liver environment discussing the different mechanisms which contribute to $T$ cell dysfunction in chronic hepatitis $B$, some of which are specifically activated in HBV infection and others which are instead common to chronic inflammatory liver diseases in general. Therapeutic interventions targeting dysregulated pathways and cellular functions will be also delineated.

Keywords: chronic HBV infection, T cell exhaustion, immune-therapy, liver environment, immunoregulatory mechanisms 


\section{INTRODUCTION}

Chronic HBV infections remain a major public health problem worldwide (1). Currently, there are no curative treatments and available therapies are effective in inhibiting $\mathrm{HBV}$ replication, but are of limited efficacy on cccDNA and HBsAg concentrations, thereby requiring long-lasting administrations to avoid the risk of HBV reactivation at withdrawal (2-4). In the search for more effective therapies, possible candidates are compounds with direct anti-viral or immune modulatory activity. The latter strategy is supported by the evidence of dysfunctional innate and adaptive immune responses in chronic active hepatitis $\mathrm{B}(\mathrm{CHB})$, which contribute to HBV persistence $(5,6)$. Recent studies unveiled a number of altered regulatory mechanisms which are key for the impairment of anti-viral immune responses in chronic infections, involving different cellular populations of the immune system, suppressive soluble mediators, up-regulation of coinhibitory molecules $(7,8)$. Most of these inhibitory mechanisms take place within the liver which is a tolerogenic organ that must prevent excessive immune responses against pathogens and antigens derived from the gut, to protect the host against severe immune-mediated damage (8). The tolerogenic properties of the liver are further enhanced by chronic inflammation which can trigger several regulatory mechanisms that make $\mathrm{T}$ cell exhaustion in HBV infection particularly severe, allowing HBV to acquire survival advantage over the immune system and to persist in the infected host.

This review will elucidate the relationship between adaptive anti-viral immune responses and the different virus- and hostrelated mechanisms particularly active within the chronically inflamed liver which favor HBV persistence. We will focus on: (i) $\mathrm{T}$ cell dysfunction, including up-regulation of coinhibitory signaling pathways, metabolic alterations, apoptotic cell death and phenotypic/functional heterogeneity of HBVspecific $\mathrm{T}$ cells; (ii) the effect of the persistent exposure of immune cells to high antigen loads; (iii) the features of the liver environment, comprising tolerogenic antigen presenting cells (APC), suppressive soluble factors, local induction of suppressive regulatory cells; (iv) potential immune-therapeutic strategies based on functional $\mathrm{T}$ cell reconstitution.

\section{T CELL EXHAUSTION IN HEPATITIS B}

During chronic HBV infections virus-specific T-cells appear deeply exhausted (5). Both CD8 and CD4 T cells, up-regulate co-inhibitory receptors which can inhibit the $\mathrm{T}$ cell function upon cross linking of their corresponding ligands (9-16). Overexpression of such co-inhibitory molecules was originally described in exhausted $\mathrm{T}$ cells from LCMV-chronically infected mice $(17,18)$, although up-regulation of inhibitory receptors is known to play a physiological role in the contraction of effector acute phase responses to avoid excessive immune pathology and autoimmune disorders. Indeed, during acute, self-limited HBV infection activated functional effector T cells display high PD-1 levels, as expression of activation, which tend to decrease during the recovery phase $(9,19-22)$ (Figure 1). However, in the setting of virus persistence, chronic antigen stimulation leads to the sustained expression of inhibitory receptors in association with $\mathrm{T}$ cell dysfunction (23). Liver-infiltrating HBV-specific T cells show maximal up-regulation of PD-1 and to a lesser extent of other co-inhibitory receptors, such as 2B4, LAG3, and CD160 $(10,11,24)$ (Figure 1). On the other hand, overexpression of several checkpoint ligands, such as PD-L1 and galectin-9, has been observed on circulating and intrahepatic antigen-presenting cells and on liver resident Kupffer cells (KCs), respectively $(14,25,26)$. Mechanistically, PD-1 engagement causes the dephosphorylation of the costimulatory receptor $\mathrm{CD} 28$ and of other TCR-associated components, thereby leading to the attenuation of the corresponding signaling and to up-regulation of inhibitory genes (27-30). Moreover, PD-1 and CTLA-4 signalings also intervene in $\mathrm{T}$ cell metabolism, by inhibiting glycolysis (31).

Exhausted HBV-specific T cells have also been depicted as more prone to apoptosis, mediated by the up-regulation of the death receptor TRAIL-2 and the pro-apoptotic mediator BIM (32-34). They harbor dysfunctional mitochondria with an abnormally elevated ROS content, have a poor capacity to use oxidative phosphorylation but are instead strictly dependent on glycolysis to meet cell energy demands $(35,36)$ (Figure 1). The relevance of these metabolic defects to $\mathrm{T}$ cell exhaustion is confirmed by the effect of mitochondria-targeted anti-oxidant compounds in the reconstitution of the anti-viral $\mathrm{T}$ cell function in vitro (36).

As described for CD8 $\mathrm{T}$ cells in cancer and in other viral infections, also $\mathrm{HBV}$-specific $\mathrm{CD} 8 \mathrm{~T}$ cells from chronically infected patients are not a functionally homogeneous population of exhausted cells, because distinct $\mathrm{T}$ cell subsets with different degrees of dysfunction have been identified $(37,38)$. Moreover, different levels of exhaustion have been reported for $\mathrm{T}$ cell subsets of different HBV antigen specificity. Higher expression of exhaustion markers, associated with a lower expansion capacity has been reported for polymerase-specific compared to core-specific CD8 cells from chronic HBV patients with low viral load $(39,40)$. Such heterogeneity has been associated to variable levels of sensitivity to functional restoration treatments in other models of $\mathrm{T}$ cell exhaustion (41-46). Thus, analysis of CD8 T cell heterogeneity in individual chronic patients is worth being investigated as a possible tool to identify those patient populations that are more likely to respond to immune therapeutic interventions.

Inhibitory checkpoint blockade has been widely studied as a strategy for immune reconstitution in chronic HBV infection. Many in vitro studies showed that PD-1/PD-L1 blockade, alone or in combination with the manipulations of other pathways, can induce variable levels of improvement of both $\mathrm{T}$ and $\mathrm{B}$ cell responses, because high PD-1 levels have also been detected in dysfunctional HBV-specific B cells from chronic HBV patients (9-12, 14, 15, 24, 47-50). A reduction of the pro-apoptotic Bim molecule expression and an increase in cytokine-producing CD8 T cells have been observed upon CTLA-4 blockade (15) and manipulation of the $2 \mathrm{~B} 4$ and Tim-3 pathways as well $(14,16)$. All different checkpoint modulation approaches, however, are not free of toxicities or immune-related adverse events, as reported in cancer patients (51-54). Moreover, additional limitations to 


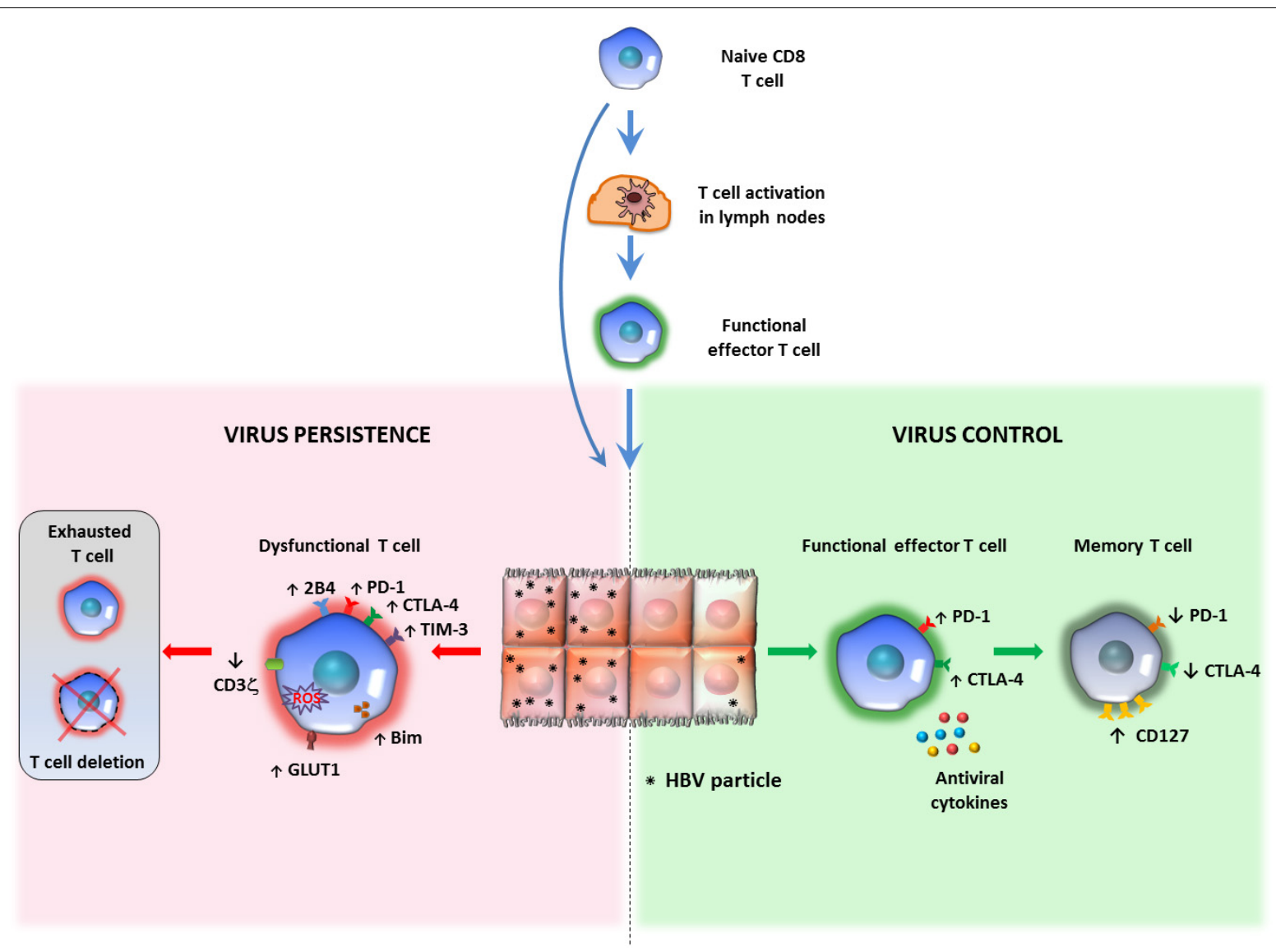

FIGURE 1 | Relationship between antigen persistence and anti-viral T cell responses in the liver. Priming of naïve CD8 T cells can occur in lymph nodes (LNs) or within the liver. In the lymph nodes naiive CD8 T cells differentiate into functional effectors; after migration to the liver, if the majority of hepatocytes are infected and express high antigen levels, virus-specific CD8 T cells undergo functional impairment or physical deletion. Some specific features of exhausted HBV-specific CD8 T cells are the over-expression of multiple inhibitory receptors and pro-apoptotic molecules, CD3ל chain down-regulation and various metabolic alterations (left pane/). If only a minor proportion of liver cells express limited amounts of viral antigens, virus specific CD8 cells can maintain efficient anti-viral activity and can promote virus control and antigen clearance (right panel). This model of T cell activation derives form studies performed in mouse models of HBV infection, but no definitive evidence is available in human infection to confirm that induction of functionally efficient effector CD8 T cells is driven by the amount of antigen (number of infected hepatocytes and amount of antigen expressed by individual liver cells) and that decline of antigen can allow restoration of functionally efficient HBV-specific CD8 T cell responses.

the in vivo use of checkpoint inhibitors is the wide heterogeneity of $\mathrm{T}$ cell responses reported in vitro to this treatment (11), and the lack of simple predictors to identify with some level of accuracy those patients who could benefit from PD-1 blockade either alone or in association with other costimulatory (for example, CD137 or OX40 stimulation) $(10,48)$, or co-inhibitory (CTLA-4 or TIM-3) $(14,15)$, pathway manipulation. The in vitro study of $\mathrm{HBV}$-specific $\mathrm{T}$ cell functionality cannot be widely used to predict response to therapeutic immune modulation in vivo because of its complexity and the need of a better standardization of functional assays. A much simpler possibility, which is being explored in different laboratories, consists in the use of phenotypic panels, including exhaustion and memory molecules, to study total, unfractionated $\mathrm{T}$ cells, in view of data indicating that exhaustion can partially affect also the overall CD4 and CD8 $\mathrm{T}$ cell populations. In this regard, the downregulation of $\mathrm{CD} 3 \zeta$ and $\mathrm{CD} 28$ has been associated to functional defects in total non-antigen-specific CD8 $\mathrm{T}$ cells in vitro and in vivo in $\mathrm{CHB}$ patients with high viral load (55). Besides, a more recent investigation confirmed the presence of both $\mathrm{HBV}$-specific and global $\mathrm{T}$ cell dysfunction mediated by multiple regulatory mechanisms, including overexpression of PD-1 and CTLA-4 by CD4 T cells (47). Moreover, additional studies have highlighted also the unconventional $\gamma \delta \mathrm{T}$ cell role in $\mathrm{HBV}$ pathogenesis both in acutely infected chimpanzees (56) and in acute and chronic patients (57). Despite some controversial findings (5861 ), a recent report described innate-like phenotypes based on the expression of Tbet/Eomes, and reduced PD-1, in association with a functional alteration in circulating $\mathrm{V} \delta 2+\gamma \delta \mathrm{T}$ cells during ALT flares in CHB patients (57).

In spite of the multifaceted nature of the immune dysfunction, an improvement of the virus-specific immunity has been detected in nucleoside analog (NUC)-treated chronically infected woodchucks upon the association of PD-L1 blockade with 
therapeutic DNA vaccination, leading to suppression of viral replication and anti-WHs antibody seroconversion in two out of three animals (62). In another study, a durable control of viremia and antigenemia was induced in 2 of 11 WHVinfected woodchucks when anti-PD-L1 was associated to NUC treatment (63).

In a recent study in human HBV infection a single dose antiPD-1 (Nivolumab) was administered to NUC treated, virally suppressed HBeAg negative chronic HBV patients who were compared to NUC treated patients who received anti-PD-1 plus therapeutic vaccination. Reduction of HBsAg titers was detected only in a limited proportion of patients who received NUC combined with anti-PD-1, with a total and persistent HBsAg loss in only one of them. Remarkably, no severe adverse events were reported, but, disappointingly, no additional effect was observed on serum HBsAg concentrations as well as on strength and quality of anti-viral $\mathrm{T}$ cell responses in the cohort of patients treated also with therapeutic vaccination (64). Low dose and short time administration of anti-PD-1 in this study don't allow, however, to draw definitive conclusions about possible future applications of this potential treatment.

In summary, in vitro data support the concept that only a proportion of patients should partially benefit from check-point blockade because only a limited percentage of patients respond in vitro and very rarely functional restoration involves simultaneously all important anti-viral cell-mediated immunological parameters. Moreover, in view of the multifactorial nature of $\mathrm{T}$ cell exhaustion pathogenesis in HBV infection, the possibility to reconstitute $\mathrm{T}$ cell functionality with a single intervention selectively focused on immune check-points seems to be highly unlikely.

This conclusion is further reinforced by the recent finding that PD-1 blockade doesn't allow complete correction of the specific epigenetic profiles which are associated with CD8 T cell exhaustion $(65,66)$. This finding gives theoretical supports to the concept that inhibition of the PD-1 pathway cannot allow persistent and complete correction of $\mathrm{T}$ cell dysfunction in chronic viral infections. Based on our present understanding of HBV-specific T cell exhaustion, PD-1/PD-L1 blockade should be likely seen as a possible adjuvant therapy to be used only in a selected group of HBV infected patients to improve T cell function and antigen responsiveness before the use of more specific HBV antigen-based therapies, such as vaccination with an appropriate antigenic composition. Moreover, the lack of an epigenetic effect provides the rationale for combining checkpoint blockade with epigenetic drugs, a therapeutic strategy already tested in the setting of anti-tumor immunotherapy.

\section{PERSISTENT T CELL EXPOSURE TO HIGH VIRAL ANTIGEN CONCENTRATIONS}

The amount of antigen expressed by liver cells is believed to influence the fate of effector CD8 cells but available data do not allow to draw definitive conclusions on this issue.
In vitro studies have addressed the interplay between infected hepatocytes and anti-viral $\mathrm{T}$ cells, showing the strengthening of the $\mathrm{T}$ cell function as antigen expression increases, suggesting that high viral antigen production is needed for efficient T-cell activation within the liver (67). On the same line, an antigen dose-dependent anti-viral $\mathrm{T}$ cell function increment has been observed also in an infectious HCV-hepatoma cell co-culture model, in which a cognate epitope expression threshold has been investigated, indicating a peptide concentration range for effector $\mathrm{T}$ cell activation (68). Also the effector:target ratio has been shown to modulate the HCV-specific T cell function in an HCV replicon system, with non-cytolytic mechanisms prevailing at lower ratio values (69). However, as in vivo high antigen loads are associated to co-inhibitory receptor/ligand overexpression, when PD-L1 expressing hepatoma cells were used, recapitulating more closely the liver environment, the $\mathrm{T}$ cell cytolytic activity resulted significantly inhibited (68). Indeed, experiments performed in animal models, evidenced a more complex $\mathrm{T}$ cell regulation in the liver environment.

By exploiting a recombinant adeno-associated viral vector system (rAAV8 transduction) to obtain selective antigen expression in mouse hepatocytes in vivo, a threshold of antigen in the liver was identified by the Bertolino's group as a crucial factor tuning $\mathrm{T}$ cell differentiation. In this model, persistent cytotoxic $\mathrm{T}$ lymphocyte (CTL) function was maintained only when less than $25 \%$ of hepatocytes were transduced, indicating that low frequencies of antigen-expressing hepatocytes can elicit a functional CD8 $\mathrm{T}$ cell response $(70,71)$. Conversely, when antigen was expressed by a high percentage of hepatocytes, virus-specific CD8 $\mathrm{T}$ cells became less responsive and over time underwent T-cell exhaustion and deletion. The phenotypic analysis of intrahepatic $\mathrm{T}$ cells isolated from mice treated with high doses of $\mathrm{rAAV}$ revealed that $\mathrm{T}$ cell exhaustion was associated with high levels of the inhibitory PD-1 and Tim-3 receptors as well as with a deficiency in cytotoxic activity and anti-viral cytokine production (71). Therefore, these data suggest that the level of antigen expression and the proportion of infected hepatocytes represent key factors in driving the development of adaptive $\mathrm{T}$ cell responses in chronic viral hepatitis.

These results are consistent with previous findings in a transgenic mouse model where intrahepatic antigen presentation triggered negative regulatory signals leading to a dysfunctional differentiation of naïve $\mathrm{CD} 8+\mathrm{T}$ lymphocytes. Indeed, naïve $\mathrm{HBV}$-specific CD8 $\mathrm{T}$ cells adoptively transferred into transgenic mice with high intrahepatic HBV antigen expression displayed proliferative responses but lacked the capacity to differentiate into functional effector $\mathrm{T}$ cells. The mechanism of $\mathrm{CD} 8 \mathrm{~T}$ cell dysfunction involved PD-1 signaling and could be rescued by CD40-dependent mDC activation (72, 73).

More recently, intrahepatic $\mathrm{T}$ cell differentiation was studied in a HBV transgenic mouse system in which $\mathrm{T}$ cell priming was restricted to the liver. In this model, naive CD8+ TCR transgenic T cells specific for HBV core were injected into major urinary protein (MUP)-core transgenic mice which exclusively expressed a non-secretable version of the HBV core protein in $100 \%$ of hepatocytes. Naïve $\mathrm{T}$ cells primed in the presence 
of high levels of HBV core antigen expressed proliferative function but failed to differentiate into functionally competent effector cells. Remarkably, even when CD8 T cell priming occurred within a liver environment where HBV core antigen expression, induced by injection with a low dose of a hepatotropic adeno-associated viral vector (AAV) encoding the HBV core protein, was limited to less than $5 \%$ of hepatocytes, effector differentiation was not supported despite much lower levels of antigen expression (74). These different $\mathrm{T}$ cell differentiation fates observed in different experimental models may likely be related not only to variable thresholds of antigen expression within the liver in different infection/transfection models, but may also depend upon TCR affinity which may restrict effector priming to high affinity TCR/MHC interactions. The evidence that a substantial reduction of hepatic antigen expression by more than 15 -fold in individual hepatocytes was still insufficient to induce a functionally efficient effector CD8 $\mathrm{T}$ cell differentiation, force some caution in predicting what antigen decline induced by therapy can actually do on the $\mathrm{T}$ cell function in chronic hepatitis patients. Future experiments in chronic patients treated with anti-viral drugs able to diminish the antigen load are mandatory to address this fundamental issue because no evidence is available at present in natural HBV infection of whether decline of antigen can actually cause functional $\mathrm{T}$ cell improvement, and, if so, which magnitude of antigen decline is required for induction of a biological effect. This is particularly puzzling in a clinical setting where multiple factors simultaneously contribute to $\mathrm{T}$ cell exhaustion and where individual patients harbor a widely heterogeneous HBV-specific CD8 $\mathrm{T}$ cell population comprising cells with different levels of functional impairment and different degrees of affinity for target cell recognition.

In another HBV-transgenic (tg) mouse model of therapeutic vaccination, based on a heterologous vaccination strategy with initial protein priming followed by recombinant Modified Vaccinia Ankara virus (MVA) vector-boost, serum HBV antigen levels have been reported to influence the immunological responsiveness to therapeutic vaccination. Indeed, vaccineinduced HBV-specific CD8+ T cell responses inversely correlated with antigenemia levels before vaccination. In mice with high antigen levels both HBsAg/MVA-S and HBcAg/MVA-core immunization failed to induce envelope and core-specific CD8 T cell responses in the spleen and in the liver, while vaccination in mice with low or intermediate antigen levels allowed expansion of anti-viral $\mathrm{T}$ cell responses and control of infection (75). Interestingly, HBV-specific CD8 T-cells were induced efficiently by therapeutic vaccination after RNAi-mediated suppression of hepatic antigen expression in highly antigenemic mice which were non-responsive to antigen stimulation before anti-viral therapy (76). Although very promising, translation of this therapeutic approach to the human natural infection may be not so easy because antigenemia in chronic patients is generally much higher and of longer duration than in this mouse model and because exposure to high antigen loads is only one of the multiple mechanisms of $\mathrm{T}$ cell inhibition which are simultaneously in place after decades of infection in chronic hepatitis patients.
In the setting of natural human HBV infection, a hierarchy of $\mathrm{T}$ cell functional efficiency was described in different conditions of HBV control in relation to serum HBsAg concentration (77). For example, maximal $\mathrm{T}$ cell functional efficiency was observed in the resolution phase of an acute self-limited hepatitis, associated with complete control of infection and lack of HBsAg in the serum, followed by intermediate levels of $\mathrm{T}$ cell functionality in chronic inactive carriers with partial control of infection and low levels of HBsAg, and finally maximal impairment of $\mathrm{T}$ cell responses in chronic active hepatitis patients with high levels of viremia and antigenemia (77).

Although level of antigen and duration of $\mathrm{T}$ cell exposure to antigenic epitopes certainly affect $\mathrm{T}$ cell functionality and responsiveness to exogenous stimulation, we must consider, however, that the level of functional $\mathrm{T}$ cell efficiency is the final result of the interplay between $\mathrm{T}$ cells and a wide range of inhibitory mechanisms (Figures 1, 2). Thus, the presence of a high antigen load in chronically infected hosts certainly represents an important obstacle for curative immunotherapeutic approaches but we must be aware that decline of antigen alone is unlikely to be sufficient for successful recovery of protective immune responses because multiple mechanisms contribute simultaneously to $\mathrm{T}$ cell exhaustion in chronic HBV infection (78).

\section{THE LIVER ENVIRONMENT}

A number of inhibitory mechanisms are active within the liver making the intrahepatic environment highly tolerogenic. The unique composition of the hepatic cell population, the expression of inhibitory checkpoint ligands and the presence of soluble regulatory mediators are some of the factors which contribute to the tolerogenic nature of the liver, which is maximal in the presence of chronic inflammation, irrespective of the etiology. Therefore, most of the mechanisms which will be described in this section are common to different chronic inflammatory liver diseases and are not specifically expressed only in chronic HBV infection (Figure 2).

\section{Tolerogenic APC}

Liver APC are not functionally mature as their counterparts in other organs (79). Hepatic dendritic cells (HDCs) and liver resident macrophages, known as KCs, which represent conventional APC, but also non-professional, unconventional APC, such as liver sinusoidal endothelial cells (LSECs), hepatic stellate cells (HSCs), as well as the hepatocytes themselves, contribute to immune tolerance, because they differ significantly from cells present in the circulation or in secondary lymphoid organs (80).

Hepatic dendritic cells show an immature phenotype, with a lower expression of MHC and costimulatory molecules (i.e., $\mathrm{CD} 40$, CD86, and CD80), poor endocytotic capacity and low IL-12 production, compared to their peripheral counterparts $(81,82)$. As reported for HDCs, low level expression of costimulatory and MHC class I and II molecules at the steady state makes also KCs, LSECs, and HSCs poorly efficient in 


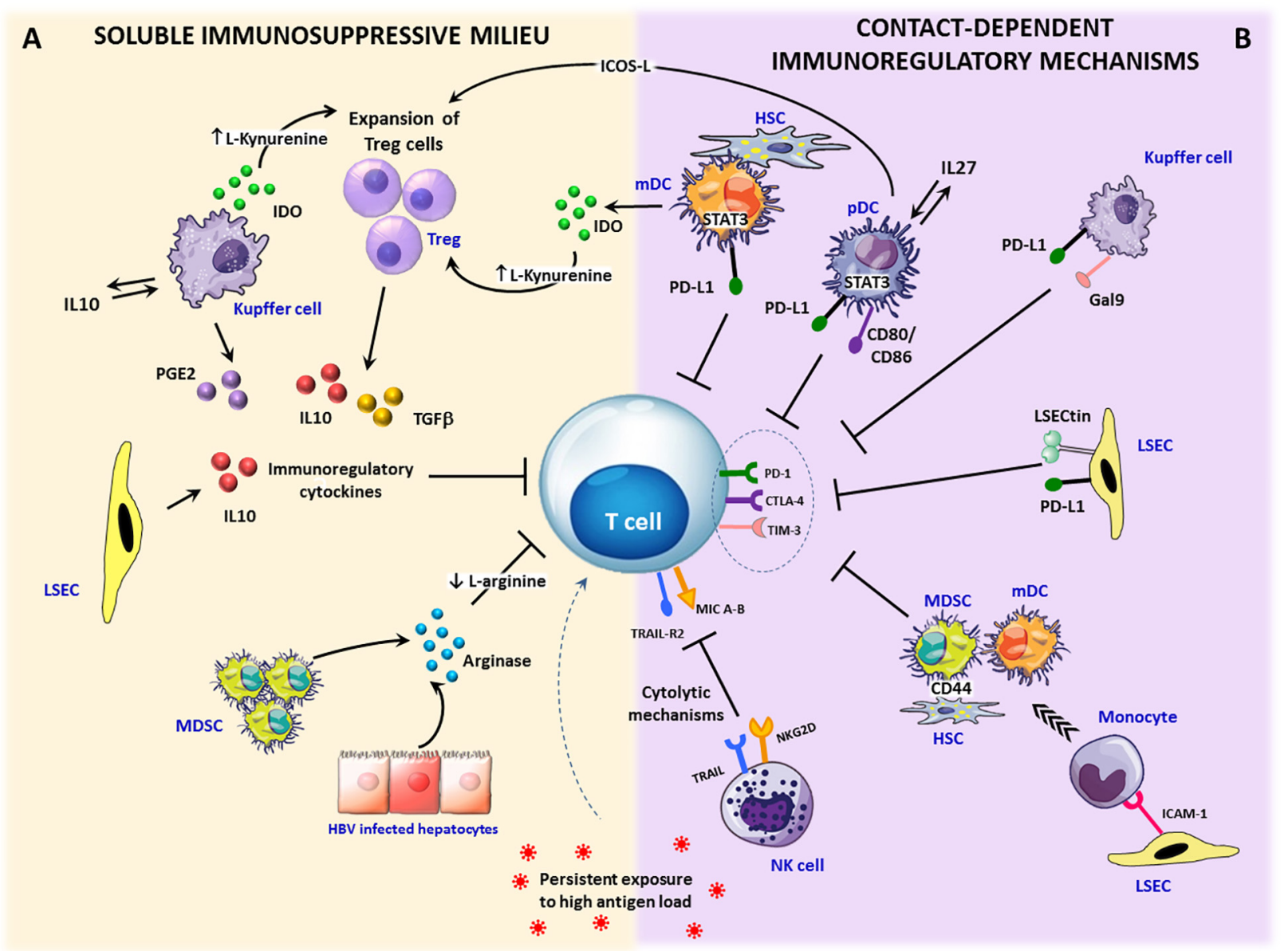

FIGURE 2 | Immunosuppressive circuits in the liver. Within the infected liver, persistent expression of viral antigens in concert with different immunoregulatory pathways drive T cell differentiation toward exhaustion. Upon inflammation, IFN- $\gamma$ stimulation activates immunosuppressive mechanisms that can be mediated by soluble factors or require cell to cell contact. (A) Soluble factors: immunosuppressive cytokines, such as TGF- $\beta$ and IL-10 can be produced by expanded regulatory T cells (Treg) as well as by stellate cells (HSCs), dendritic cells (DCs) and Kupffer cells (KCs). In addition, a number of liver infiltrating cells, such as monocytes, macrophages and dendritic cells, can release the tryptophan-degrading enzyme indoleamine 2,3-dioxygenase (IDO), which causes either tryptophan depletion with consequent dampening of T cell proliferation and function or the generation of toxic catabolites, such as kynurenines, which can cause T cell apoptosis and CD4 differentiation in Treg cells. Another key soluble mediator is represented by arginase, released by damaged hepatocytes and myeloid-derived suppressor cells (MDSC), inducing arginine depletion. Lack of arginine determines CD3 $\zeta$ downregulation and suppression of T cells proliferation. Moreover, the enzyme cyclooxygenase-2 produced by activated KCs participates in the synthesis of the immunosuppressive prostaglandin E2 (PGE-2). (B) Contact-dependent mechanisms: antigen-specific CD8 T cells can be killed by NK cells through NKG2D- and TRAIL-dependent lysis. Over-expression of inhibitory ligands (e.g., PD-L1, Galectin-9) on liver endothelial sinusoidal cells (LSECs), dendritic cells, KCs, and stellate cells facilitates the triggering of T cell inhibitory pathways. In addition, inflammatory monocytes recruited into the liver through ICAM-1 expression on LSECs can differentiate into myeloid-derived suppressor cells by a CD44-dependent mechanism driven by activated stellate cells. Finally, Treg cell expansion and IL-10 production can be caused by pDCs and mDCs via the ICOS/ICOSL-mediated interaction or IDO secretion.

T cell stimulation (83-88). They can also induce CD8 T cell apoptosis by Fas-FasL interaction, as described for KCs following reactive-oxygen species (ROS) production induced by FasL upregulation on their surface $(80,89)$, and for HSCs through induction of intracellular signaling pathways triggered by PDL1 and B7-H4 crosslinking (90-93). Hepatocyte priming of CD8 $\mathrm{T}$ cells generally results either in clonal $\mathrm{T}$ cell deletion by BIMmediated apoptosis $(90,94)$, or in dysfunctional CD8 T cells without effector functions (74), as already discussed in detail in the previous section. HSCs and LSECs can also inhibit CD8 T cell priming/activation through a TRAIL and ICAM-dependent mechanism or through LSECtin-CD44 interaction, respectively (95). Moreover, antigen presentation by all these cells is often associated to the secretion of immune-regulatory mediators, such as IL-10, TGF- $\beta$, prostaglandin E2 (PGE2), and to the up-regulation of PD-L1 (87, 96-100).

High co-inhibitory molecule expression by HDCs can be induced by the nucleotide-binding oligomerization domain 2 (NOD2) signaling, significantly more expressed in hepatic plasmacytoid (pDCs) than in conventional or myeloid (mDCs) dendritic cells, which is also responsible for their low IFN- $\alpha$ secretion (101). The CD141+ subset of mDCs, which produces 
IL-12 and plays a central role in antigen cross-presentation (102), have also been reported in healthy human livers to express high levels of the tolerogenic molecules immunoglobulinlike transcript 3 (ILT3) and ILT4 (103), which can inhibit T cell activation through tyrosine-based inhibitory motifs (ITIMs) contained in their cytoplasmic tails $(104,105)$.

In chronic HBV patients hepatic and peripheral dendritic cells have been reported by several studies to be functionally impaired, with a possible inhibitory effect of viral antigens on their function (106-112). However, this concept is still widely debated (113) because other studies did not observe any significant alterations of the DC function $(114,115)$.

Among the possible DC defects in chronic hepatitis $\mathrm{B}$, a reduced production of the immunoregulatory cytokine osteopontin (OPN) has been described and suggested to represent a potential cause of TH1 response impairment (116). Impaired DCs maturation and function in chronically HBVinfected patients has also been associated with an altered expression of innate sensors, such as TLRs (117-120).

Although most studies on DCs in chronic HBV infection have been performed on peripheral cells, a recent report shows alterations in frequency and basal activation status of DC subsets from both blood and liver of chronic HBV patients compared to healthy controls. In addition, also a defective up-regulation of maturation markers upon TLRs triggering was reported in this study, but only circulating DCs displayed a significant impairment of cytokine production in response to TLR agonist stimulation (118). The poor effect on the NK cell cytolytic function by TLR9 ligand stimulation of HDCs was related to reduced OX40L expression as well as to high plasma IP-10 and HBV antigen levels (121). Mechanistically, HBV particle internalization can block $\mathrm{pDCs} I F N \alpha$ production by inhibiting TLR9 signaling, through down-regulation of TLR9 transcription (122), which can also be indirectly caused by TNF $\alpha$ and IL-10 production induced by HBsAg on monocytes (123).

Also KCs have a role in the induction of tolerance to HBV. This is supported by the observation in a mouse model of $\mathrm{HBV}$ infection that earlier $\mathrm{HBV}$ clearance in older mice was accompanied by a severe reduction in $\mathrm{KC}$ numbers, concomitant with a sharp induction of TNF $\alpha$-producing Ly6C+monocytes, followed by the proliferation of IFN $\gamma+\mathrm{TNF} \alpha+$ CD8 T cells. Instead, younger mice, which failed to clear the virus, maintained high frequencies of IL-10-secreting KCs (124).

Functional skewing of the $\mathrm{T}$ cell response toward a $\mathrm{TH} 2$ profile can also be supported by macrophages with a predominant M2-like phenotype, known to be potent immune suppressor cells (125), detected at high frequencies in a humanized mouse model of persistent HBV infection (126). The evidence that KCs and liver infiltrating macrophages show up-regulation of the CD86 co-stimulatory molecule, which is known to drive $\mathrm{T}$ cell differentiation toward a functional TH2 profile (127), detected by immunohistochemistry staining of liver biopsies from chronic HBV patients, further support this finding (128). A direct interaction between HBsAg and KCs with HBsAg uptake, was documented both in vitro and in ex vivo isolated KCs from $\mathrm{CHB}$ patients (129). In vitro exposure to $\mathrm{HBV}$ antigens preferably induced TGF- $\beta$, rather than pro-inflammatory cytokine secretion by primary rat KCs (130); moreover, $\mathrm{HBV}$ antigen interaction with TLR2 on KCs caused T cell inhibition through IL-10 secretion $(131,132)$ and TLR2 knockout or KC depletion resulted in enhanced HBV elimination and improved CD8+ $\mathrm{T}$ cell responses in mice (131). This inhibitory effect mediated by HBV proteins was further documented by more recent studies showing that HBV protein uptake by intrahepatic macrophages from $\mathrm{CHB}$ patients can favor anti-inflammatory over pro-inflammatory functions and can ultimately promote hepatocyte infection (133).

Despite these tolerogenic features, the liver environment must ensure a fine tuning of divergent functions to guarantee tolerance to antigens introduced through the gut, but also to initiate efficient immune responses needed for pathogen control. For example, in case of liver inflammation KCs secrete pro-inflammatory cytokines and can mediate full CD8 $\mathrm{T}$ cell differentiation $(83,134)$, while the propensity of hepatic DCs toward immunogenicity or tolerance has been associated to their lipid content and metabolism. Indeed, high lipid content can make HDCs able to secrete high levels of pro-inflammatory cytokines and to efficiently activate T or NK cells, while low lipid content is associated with tolerance induction (135).

Overall, many pieces of evidence indicate a preferential antiinflammatory response induction by antigen-presenting cells in chronic HBV infection, suggesting the possibility of a direct innate immunity inhibition by the virus itself (119), which has also been reported to be poorly sensed by innate immunity sensors, behaving as a stealth virus (136). Interference of viral proteins with innate signaling pathways (119) represents another theoretical reason why reduction of antigenemia may be relevant in the perspective of therapeutic strategies for $\mathrm{CHB}$ based on functional immune reconstitution. In addition to novel direct anti-viral agents acting at different levels of the HBV life cycle (see below in the "Perspectives for novel therapeutic strategies" section), stimulation of pathogen recognition receptors, such as TLRs and Retinoic acid-Inducible Gene I (RIG)-like receptors (137) represents a possible strategy, currently under evaluation, to increase the efficiency of anti-viral immune activation.

Dendritic cells manipulation has also been proposed. Indeed, administration of HBV peptide-loaded DCs was reported to elicit functional HBV-specific CD8 cells and to reduce the viral load in Hepato-HuPBL mice (138) and a targeted antigen delivery to DCs was proven to efficiently induce local immunity to hepatotropic viruses in mice (139). Interestingly, in the context of cancer immunotherapy, PD-L1 silenced DCs were used for a DC vaccine that induced potent T cell responses (140). Finally, IL-2 administration could recover dysfunctional HBV-specific CD8 cells originated by an inefficient hepatocyte priming in HBV transgenic mice (74).

\section{Soluble Factors}

As a result of its peculiar cell population, the liver microenvironment is enriched in soluble factors with immunosuppressive function (Figure 2A). Not only the immunoregulatory cytokines IL-10 and TGF- $\beta$ are preferentially secreted over other pro-inflammatory cytokines by several types of hepatic cells (i.e., dendritic cells, macrophages/monocytes, LSECs) (141), but also an abundance of other regulatory 
mediators has been detected within the liver. Indeed, constitutive expression by different liver infiltrating cells (e.g., dendritic cells, regulatory myeloid cells) (141, 142), of tryptophan2,3-deoxygenase (TDO), or Indoleamine 2,3-dioxygenase (IDO) which are tryptophan-degrading enzymes, can lead to tryptophan depletion and the formation of toxic metabolites, such as kynurenines $(143,144)$. These factors have been shown to constrain T and NK cell proliferation (145) and to induce T cell apoptosis $(143,144)$.

The shortage of another essential amino acid, i.e., L-arginine, causing $\mathrm{T}$ cell arrest in the G0/G1 phase and CD3 $\zeta$ chain downregulation, is due to an excess of arginase derived from damaged hepatocytes (146) and other liver-infiltrating cells (147). In HBVinfected patients the latter mechanism was demonstrated both in acutely and in chronically infected subjects and could be corrected in vitro by $\mathrm{T}$ cell transfection of $\mathrm{CD} 3 \zeta$ or replenishment of the amino acid arginine required for its expression $(19,55)$.

Interestingly, a granulocytic subset of myeloid-derived suppressor cells (gMDSC), which release arginase I upon degranulation, was demonstrated to be expanded in $\mathrm{CHB}$ patients with high HBV replication levels without liver necroinflammation, highlighting the capacity of these cells to contain tissue damage by limiting arginine supply to T cells (148).

\section{Local Induction of Regulatory Cells}

In addition to HSCs, KCs, and macrophages, the liver is enriched in populations of regulatory cells, such as myeloid derived suppressor cells (MDSCs) and regulatory T cells (Tregs), that can promote tolerance by producing immunosuppressive cytokines (IL-10 and TGF- $\beta$ ) and by expressing high levels of coinhibitory ligands, such as PD-L1 and Galectin-9 (Figures 2A,B). Importantly, the direct contact between circulating $\mathrm{T}$ cells and resident regulatory cells is favored by the slow blood flow in liver sinusoids and by the unique liver architecture, which is characterized by the presence of sinusoidal wall fenestrations which facilitate cell to cell contact (85).

\section{Myeloid Derived Suppressor Cells}

Myeloid cells play a key regulatory role within the liver contributing to the outcome of immune responses, thanks to their functional plasticity. In fact, they can differentiate from monocytes into macrophages, monocyte-derived dendritic cells or myeloid suppressor cells. During liver inflammation, inflammatory monocytes can be recruited into the liver as a result of ICAM-1 (CD54) expression on LSECs (141). They can subsequently differentiate into myeloid-derived suppressor cells by a CD44-dependent mechanism driven by activated stellate cells (141), as shown by the possibility to prevent acquisition of the suppressive phenotype by blocking CD44-mediated interaction between monocytes and HSCs (149). During prolonged hepatic inflammation, MDSCs inhibit immune responses through different mechanisms, including IL10 and TGF- $\beta$ secretion, as well as production of arginase 1 and reactive oxygen species (ROS) (150). Expansion and suppressive function of MDSCs was reported to be modulated by cysteine-rich protein 61 (CCN1), a multifunctional protein highly expressed in impaired cholangiocytes and hepatocytes. This has been described in primary biliary cholangitis (PBC) but it may likely represent a general mechanism of MDSC modulation shared by chronic liver inflammations of different etiology (151).

As already mentioned, the immunosuppressive function of MDSCs was described in chronic HBV infection where gMDSC could dampen $\mathrm{HBV}$-specific $\mathrm{T}$ cell responses in a arginasedependent manner, documenting the capacity of expanded arginase-expressing gMDSCs to regulate liver immunopathology (148). A recent study in chronically $\mathrm{HBV}$ infected patients with high levels of HBsAg revealed the capacity of MDSCs to promote immune dysfunction through the induction of regulatory $\mathrm{T}$ cells, primarily via TGF- $\beta$ and IL-10 dependent signaling pathways. Interestingly, a year tenofovir treatment did not result in the immune restoration of the regulatory MDSC and Treg populations (152). In addition, circulating MDSCs were significantly expanded in patients with HBV-related acute-onchronic liver failure (ACLF) and closely associated with disease progression and severity. In this setting, $\mathrm{CD} 3 \zeta$ chain expression was decreased in T cells and negatively correlated with MDSC frequency (153).

Monocyte differentiation within the liver can also be driven by TLR-9 signaling toward the acquisition of anti-viral protective properties through the formation of inflammatory monocyte aggregates, called iMATEs, where virus-specific CD8 cells can expand upon OX40- and CD28-mediated signaling initiated by inflammatory dendritic cells of monocyte origin (154). This unique iMATEs structure, which, however, seems to be generated selectively in the mouse liver, can contribute to chronic virus infection control. iMATE formation induced by systemic TLR9 treatment has also been reported to induce effector CD8 T cell expansion and control of tumor growth in a murine hepatoma model (155).

Such functional plasticity of MDSCs represents a unique challenge for future therapeutic interventions in the setting of chronic liver disease (156). Indeed, all these results suggest that a therapeutic regiment that either blocks MDSC suppressive functions and Treg amplification or supports iMATES formation facilitating CD8 $\mathrm{T}$ cell proliferation might represent a potential strategy to cure HBV-related liver disease. However, further studies of this unique regulatory cell population are needed to better characterize its real therapeutic potential.

\section{Treg Expansion}

During viral infection, regulatory $\mathrm{T}$ cells are recruited into the inflamed liver and compete with effector CD8 T cells for IL-2, limiting the amplification of virus-specific T cell responses (8). Both $\mathrm{mDCs}$ and $\mathrm{pDCs}$ have been described to promote Treg proliferation through a mechanism mediated by STAT3 signaling (102, 157-159). Specifically, the expansion of Treg cells, which can inhibit $\mathrm{T}$ cell responses either by direct cell-cell contact or by secretion of suppressive cytokines, can be caused by plasmacytoid dendritic cells (pDCs) through an IL27-based circuit which can lead to PD-L1 expression and subsequent Treg proliferation (158, 160). pDCs further foster T cell tolerance by stimulating IL-10 producing Tregs via an ICOS/ICOSL-mediated interaction (102, 159). In parallel, mDCs can also promote Treg expansion and $\mathrm{T}$ cell apoptosis as a result of the cross-talk with HSCs, leading 
to PD-L1 up-regulation and IDO induction, and subsequent generation of immunosuppressive kynurenine compounds (161163). Recent findings highlighted a novel OX40L + DC subset able to selectively expand Tregs, which plays an essential role in Treg homeostasis maintenance under inflammatory conditions; indeed, co-culture of DCs from GM-CSF treated mice and CD4+ $\mathrm{T}$ cells induced an increase in Treg proliferation in an OX40L dependent manner (164). Treg cell expansion can be also stimulated by LSECs and IFN- $\gamma$ activated stellate cells in a PD-L1 independent manner $(141,161)$. LSECs are the major liver cells responsible for TGF- $\beta$ dependent hepatic FoxP3+ Treg induction, thanks to their unique capacity to secrete TGF- $\beta$ and to bind exogenous LAP/TGF- $\beta$ to their membrane through the anchor molecule GARP. By this mechanism, LSEC-induced Tregs have been reported to become functional suppressor cells in a mouse model of autoimmune encephalomyelitis (165). Beyond this tolerogenic role, LSECs have been recognized as a population that can efficiently stimulate naïve CD8 $\mathrm{T}$ cells to differentiate into a liver-primed memory $\mathrm{T}$ cell population providing protection and contributing to clearance of viral infections $(8,166)$.

Also HSCs can function as tolerogenic regulators in the liver, by enhancing TGF- $\beta$-dependent Treg generation and inhibiting TGF- $\beta$ dependent Th17 differentiation, via a retinoic acid (RA)mediated mechanism (167). HSCs have been associated with the production of TGF- $\beta$ and all-trans retinoic acid (ATRA), both important for Treg differentiation (168). In particular, generation of FoxP3+ Tregs have been reported to occur in the presence of DCs and low concentrations of TGF- $\beta$ in an ATRA-dependent manner, since blocking experiments of RA-RA receptor interaction inhibited HSC-induced FoxP3 expression (169). Furthermore, a recent report indicates that HSCs from HBV patients with advanced liver fibrosis play an important role in modulating the intrahepatic Treg population via a PGE2/EP2 and EP4 pathway (170).

\section{T Cell Killing by NK Cells}

NK cells are highly enriched within the liver where they exert a key role in anti-viral control but can also exert a regulatory effect with possible inhibition of adaptive immune responses $(32,34)$ (Figure 2B). Initial studies performed in LCMV-infected mice demonstrated that $\mathrm{T}$ cells are susceptible to NK-cellmediated killing $(171,172)$. The elimination of activated $\mathrm{T}$ lymphocytes by NK cells can be mediated by NKG2D- and TRAIL-dependent mechanisms, as demonstrated in vitro (34, 173-175) and in LCMV infected mice in vivo (172). Moreover, regulation of T-cell responses by a direct perforin-dependent NKcell-mediated elimination of CD4 T cells leading to the loss of help for CD8 $\mathrm{T}$ cells was observed in the same murine model of chronic viral infection (171).

In this negative modulation of $\mathrm{T}$ cell responses by $\mathrm{NK}$ cell killing, the NK cell NCR1 (NKp46)-receptor may have an important role and inhibition of NCR1 ligand expression on T cells by type I IFN signaling can protect T cells from NK cell killing allowing $\mathrm{T}$ cell evasion from NCR1 mediated NK cell $\operatorname{attack}(176)$.
In chronic HBV patients NK cells are more pathogenic than protective because defective in cytokine production but efficiently able to express cytolytic function $(32,34)$. Moreover, apoptosis of HBV-specific CD8 T cells up-regulating the death-inducing receptor TRAIL-R2 can be caused by TRAIL-positive NK cells in chronically infected HBV patients (34). By these mechanisms NK cells can deeply impair T cell responses, protecting the host from fatal immunopathology during viral infections but also diminishing the anti-viral activity of effector $\mathrm{T}$ cells, thereby contributing to the exhausted $\mathrm{T}$ cell phenotype of chronic infections. Thus, therapeutic strategies aimed at promoting the protective over the pathogenic and inhibitory effects of NK cells may represent potential options to treat chronic HBV infection.

\section{PERSPECTIVES FOR NOVEL THERAPEUTIC STRATEGIES}

Immune reconstitution of functionally efficient $\mathrm{T}$ cell responses can be crucial for the cure of chronic HBV infection. An efficient strategy to improve the $\mathrm{HBV}$-specific $\mathrm{T}$ cell function should probably target multiple mechanisms, because the protective anti-viral $\mathrm{T}$ cell response is affected by multiple factors simultaneously during chronic infections. Decline of antigen can allow correction of a single inhibitory mechanism and is expected for this reason to be insufficient alone for successful immune restoration. It thus represents only a part of the overall functional reconstitution strategy which should be put in place to cure HBV infection. Instead of currently available NUCs, which are poorly effective in diminishing HBV antigen concentrations, new and more efficient antivirals should be employed in the future, once clinically available, to reduce more rapidly and more efficiently the antigen load and the number of infected hepatocytes. They include RNA interference (RNAi) molecules, which can directly target HBV mRNAs, allowing reduction in HBsAg serum titers (177), HBV capsid assembly inhibitors and nucleic acid polymers (NAPs), as HBsAg release inhibitors (178180). Since decline of antigen alone is expected to be insufficient, additional mechanisms should be targeted to further improve $\mathrm{T}$ cell responsiveness. Immune checkpoint blockade represents a possibility, but also metabolic and epigenetic modulations are very promising. In addition, recent studies performed in a transgenic mouse model of neonatal HBV infection, which closely recapitulates the immunological events occurring in the early immune tolerant phase of chronic HBV infection, indicate that IL-2, rather than checkpoint blockade, can improve defective $\mathrm{T}$ cell responses (74). As predictable, IL-2 treatment induced functional improvement only of HBV-specific CD8 T cells from immune-tolerant, but not immune-active chronic HBV patients.

In the perspective of a therapeutic correction of $\mathrm{T}$ cell exhaustion, a crucial limitation is represented by the incomplete information we have on level and quality of $\mathrm{T}$ cell functional reconstitution which is needed to achieve control of chronic HBV infection.

In order to address this issue, the optimal comparator to define level and quality of the $\mathrm{T}$ cell response to be restored for control of infection would be represented by patients able to 
resolve an acute infection spontaneously. However, one major limitation to the definition of the immune parameters in these subjects is represented by the heterogeneity of $\mathrm{T}$ cell reactivities in relation to the time elapsed from the initial exposure to the virus, which is generally undefined. Certainly the study of adult-onset infections with known duration evolving either toward resolution or chronicization would be crucial for the identification of $\mathrm{T}$ cell features associated to virus control. Nonetheless, the paucity of clinically overt acute HBV infections nowadays and the much greater rarity of those chronically evolving make such a study hardly feasible. In addition, difficult recruitment of a significant control patient cohort is further compounded by technical curbs due to patients' HLA heterogeneity, as most of the studied T cell epitope specificities are mainly limited to the HLA-A*02 restriction, which is only prevalent in the Caucasian population.

Even more important, still unknown, is whether the maximal improvement of $\mathrm{T}$ cell responses that a given chronic patient can reach after long-term exposure to HBV and its antigens is sufficient for complete and durable HBV cure. In the lack of definitive data ruling out the possibility that $\mathrm{T}$ cell functional defects derived from decades of $\mathrm{T}$ cell/virus interplay are only partially and insufficiently reversible by therapeutic $\mathrm{T}$ cell correction strategies, an alternative possibility to overcome $\mathrm{T}$ cell exhaustion is represented by the in vitro generation and expansion of functionally efficient, genetically engineered HBVspecific $\mathrm{T}$ cells for adoptive transfer to chronically infected patients. To this purpose, autologous $\mathrm{T}$ cells of HBV-unrelated specificity have been engineered to express $\mathrm{HBV}$-specific TCR able to recognize HLA/peptide complexes in a HLA restricted manner (TCR-redirected T cells) or chimeric antigen receptors (CAR) composed of synthetic antibody fragments, combined with costimulatory domains, such as the $\mathrm{CD} 28$ and the $\mathrm{CD} 3$ zeta molecules, that allow the receptor to recognize viral antigens on infected cells in a HLA independent way, without the need of antigen processing (181-184). Thus, an important advantage of CAR T cells over TCR-redirected T cells is that CAR T cells can be used in all patients, irrespective of their HLA profile, while TCR-redirected $\mathrm{T}$ cells can only be used in patients with the appropriate HLA haplotype and can recognize only individual epitopes generated by intracellular antigen processing.

Potential problems related to these $\mathrm{T}$ cell transfer approaches are the possible risk of severe liver damage and the possible inhibitory effect on transferred effector $\mathrm{T}$ cells of the tolerogenic liver environment. To reduce cell lifespan and limit the risk of uncontrolled proliferation with progressive liver damage, a transient expression of the modified TCR has been developed by mRNA electroporation (185). Moreover, combination of checkpoint blockade and CAR T cell therapy (186), as well as shRNA knockdown of PD-1 in TCR-redirected T cells (187) have been used to prevent immunosuppressive mechanisms mediated by inhibitory co-receptors (188). In addition, CAR T cells have recently been further engineered by over-expressing the canonical AP-1 transcription factor c-Jun to render them resistant to exhaustion. These cells showed different chromatin accessibility, enhanced expansion and functional capacity, and improved anti-tumor activity in five different tumor mouse models in vivo (189).
In summary, $\mathrm{T}$ cell modulation remains a promising therapeutic strategy to cure chronic HBV infection, but the proof of concept that it can actually work in this clinical context still remains to be provided. A number of different elements contribute to the complexity of its practical application: first of all, the still partial knowledge of the immunological correlates of protection in HBV infection. The functional efficiency of HBVspecific $\mathrm{T}$ cell responses is certainly essential for a final and persistent control of infection, but we don't know whether a selective improvement of the $\mathrm{T}$ cell function can be sufficient to cure infection. This uncertainty raises the issue of which other effectors of the immune system should be modulated in combination with a functional $\mathrm{T}$ cell reconstitution, in consideration of the evidence that also intracellular innate responses and NK cells are defective in chronic HBV infection $(32,190)$. This opens in turn a series of additional questions. In particular, the number of different therapeutic interventions to be used simultaneously or sequentially in order to restore a functional immune system, considering that $\mathrm{T}$ cell dysfunction per se is multifactorial and may require for its correction the coordinated application of different therapeutic approaches. This is particularly relevant in consideration of the fact that available therapies are easy to take and almost totally free of side effects and that chronic HBV patients under therapy feel absolutely well (191). This implies that new therapies should be easy to take, free of important side effects, and highly effective against the virus in a short time. In light of these considerations, all different strategies exposing the patient to the risk of a strong stimulation of T cells of HBV-unrelated specificity (i.e., epigenetic therapies, checkpoint inhibition) or of extensive and severe liver damage (i.e., therapeutic vaccines) or the combination of different approaches may be ethically problematic. This concern may also apply to the adoptive $\mathrm{T}$ cell transfer of genetically engineered $\mathrm{T}$ cells which is also technically very complex for a wide application in the clinical practice.

\section{FINAL REMARKS}

A number of specific drugs able to intervene on the different steps of the HBV life cycle and on different mechanisms involved in the pathogenesis of $\mathrm{T}$ cell exhaustion are now available and under clinical evaluation. In a first step of therapy, new direct anti-viral drugs acting on HBV replication, antigen production and liver inflammation may be needed to make immune therapies more effective, because their efficacy in improving the $\mathrm{T}$ cell function is believed to be affected by the negative regulatory mechanisms triggered by the exposure to high antigen quantities and by the environment of the chronically inflamed liver. This initial step of anti-viral therapy may be also essential to diminish the risk of severe liver pathology which may follow a strong activation of anti-viral effector $\mathrm{T}$ cells induced when the percentage of infected liver cells is elevated. Assuming that decline of antigen and control of liver inflammation may be insufficient for optimal restoration of anti-viral $\mathrm{T}$ cell functions, the possible choice for a second step of therapy to further overcome T cell exhaustion is in principle between checkpoint blockade, metabolic correction 
and epigenetic modulation strategies. On one hand, correction of mitochondrial and proteasomal defects in chronic HBV infection by the use of mitochondrial targeted anti-oxidants and polyphenolic compounds seems to be comparably or even more efficient than PD-1/PD-L1 blockade in functional $\mathrm{T}$ cell restoration in vitro with very limited effects on $\mathrm{T}$ cells of HBV-unrelated specificity (192). On the other hand, epigenetic modulators are expected to be highly effective on $\mathrm{T}$ cell responses given the massive transcriptional downregulation detected in exhausted HBV-specific CD8 cells (36), but their use in vivo may be precluded by their potentially severe side effects.

Once $\mathrm{T}$ cell exhaustion is maximally corrected and responsiveness to antigen stimulation is optimally reacquired, effector $\mathrm{T}$ cell responses will likely need to be boosted in a third step of therapy by vaccines containing not only HBsAg and HBcAg but also polymerase, in consideration of its high immunogenicity and the severe level of exhaustion of pol-specific CD8 $\mathrm{T}$ cells reported in chronic $\mathrm{HBV}$ infection $(39,40)$.

Finally, an important goal for future research will be also to develop reliable predictors of response to immune therapies to be used in individual patients. Indeed, it is becoming increasingly clear that chronic patients are a heterogeneous population with variable levels of $\mathrm{T}$ cell functionality, which can probably confer propensity to respond more or less efficiently to immune modulation $(37,38)$. Identification of cell-mediated immunologic profiles predictive of response to immune modulation will be pivotal for the success of immune therapies because we can

\section{REFERENCES}

1. Ward JW, Hinman AR. What is needed to eliminate hepatitis B virus and hepatitis C virus as global health threats. Gastroenterology. (2019) 156:297310. doi: 10.1053/j.gastro.2018.10.048

2. Grossi G, Viganò M, Loglio A, Lampertico P. Hepatitis B virus long-term impact of antiviral therapy nucleot(s)ide analogues (NUCs). Liver Int. (2017) 37:45-51. doi: 10.1111/liv.13291

3. Levrero M, Subic M, Villeret F, Zoulim F. Perspectives and limitations for nucleo(t)side analogs in future HBV therapies. Curr Opin Virol. (2018) 30:80-9. doi: 10.1016/j.coviro.2018.04.006

4. Zoulim F, Lebossé F, Levrero M. Current treatments for chronic hepatitis B virus infections. Curr Opin Virol. (2016) 18:109-16. doi: 10.1016/j.coviro. 2016.06.004

5. Bertoletti A, Ferrari C. Adaptive immunity in HBV infection. J Hepatol. (2016) 64:S71-83. doi: 10.1016/j.jhep.2016.01.026

6. Maini MK, Gehring AJ. The role of innate immunity in the immunopathology and treatment of HBV infection. J Hepatol (2016) 64:S60-70. doi: 10.1016/j.jhep.2016.01.028

7. McLane LM, Abdel-Hakeem MS, Wherry EJ. CD8 T cell exhaustion during chronic viral infection and cancer. Annu Rev Immunol. (2019) 37:457-95. doi: 10.1146/annurev-immunol-041015-055318

8. Knolle PA, Böttcher J, Huang L-R. The role of hepatic immune regulation in systemic immunity to viral infection. Med Microbiol Immunol. (2015) 204:21-7. doi: 10.1007/s00430-014-0371-0

9. Boni C, Fisicaro P, Valdatta C, Amadei B, Di Vincenzo P, Giuberti T, et al. Characterization of hepatitis B Virus (HBV)-Specific T-Cell Dysfunction in Chronic HBV Infection. J Virol. (2007) 81:4215-25. doi: 10.1128/JVI. 02844-06

10. Fisicaro P, Valdatta C, Massari M, Loggi E, Ravanetti L, Urbani S, et al. Combined Blockade of Programmed Death-1 and Activation of CD137 predict that only a proportion of chronic HBV patients will take advantage from immune modulation.

Thus, the possible scenario that recent research results allow to depict for a near future would be a therapy for chronic hepatitis B with new direct anti-viral compounds started after an immunological characterization of individual treated patients to predict their likelihood of responsiveness to immune therapies aimed at functional $\mathrm{T}$ cell reconstitution. Only patients predicted to be immunologically responsive will receive this second step of therapy based on immune modulation (i.e., metabolic or checkpoint modulators) and therapeutic vaccination, either sequentially or simultaneously.

\section{AUTHOR CONTRIBUTIONS}

$\mathrm{PF}, \mathrm{CB}$, and $\mathrm{VB}$ : design and writing of the manuscript. $\mathrm{MR}$, $\mathrm{GA}$, and DL: contribution to figure drawing. IM, AV, and AZ: contribution to the selection of the references to quote. AP and GM: discussion of the concepts to be introduced in the text. CF: critical revision of text and figures.

\section{FUNDING}

This work was supported by a grant from Regione EmiliaRomagna, Italy (Programma di Ricerca Regione-Università 2010-2012; PRUa1RI-2012-006), and by a grant from the Italian Ministry of Health (Ricerca Finalizzata RF 2013-02359333).
Increase Responses of Human Liver T Cells Against HBV, But Not HCV. Gastroenterology. (2012) 143:1576.e-85.e. doi: 10.1053/j.gastro.2012.08.041

11. Bengsch B, Martin B, Thimme R. Restoration of HBV-specific CD8+ T cell function by PD-1 blockade in inactive carrier patients is linked to $\mathrm{T}$ cell differentiation. J Hepatol. (2014) 61:1212-9. doi: 10.1016/j.jhep.2014. 07.005

12. Raziorrouh B, Heeg M, Kurktschiev P, Schraut W, Zachoval R, Wendtner $\mathrm{C}$, et al. Inhibitory phenotype of HBV-specific CD4+ T-cells is characterized by High PD-1 expression but absent coregulation of multiple inhibitory molecules. PLoS One. (2014) 9:e105703. doi: 10.1371/journal.pone.0105703

13. Dong Y, Li X, Zhang L, Zhu Q, Chen C, Bao J, et al. CD4+ T cell exhaustion revealed by high PD-1 and LAG-3 expression and the loss of helper $\mathrm{T}$ cell function in chronic hepatitis B. BMC Immunol. (2019) 20:27. doi: 10.1186/ s12865-019-0309-9

14. Nebbia G, Peppa D, Schurich A, Khanna P, Singh HD, Cheng Y, et al. Upregulation of the Tim-3/galectin-9 pathway of T cell exhaustion in chronic hepatitis B virus infection. PLoS One. (2012) 7:e47648. doi: 10.1371/journal. pone. 0047648

15. Schurich A, Khanna P, Lopes AR, Han KJ, Peppa D, Micco L, et al. Role of the coinhibitory receptor cytotoxic $\mathrm{T}$ lymphocyte antigen-4 on apoptosisProne CD8 T cells in persistent hepatitis B virus infection. Hepatology. (2011) 53:1494-503. doi: 10.1002/hep.24249

16. Raziorrouh B, Schraut W, Gerlach T, Nowack D, Grüner NH, Ulsenheimer A, et al. The immunoregulatory role of CD244 in chronic hepatitis B infection and its inhibitory potential on virus-specific CD8+ T-cell function. Hepatology. (2010) 52:1934-47. doi: 10.1002/hep.23936

17. Barber DL, Wherry EJ, Masopust D, Zhu B, Allison JP, Sharpe AH, et al. Restoring function in exhausted CD8 $\mathrm{T}$ cells during chronic viral infection. Nature. (2006) 439:682-7. doi: 10.1038/nature04444

18. Blackburn SD, Shin H, Haining WN, Zou T, Workman CJ, Polley A, et al. Coregulation of $\mathrm{CD} 8+\mathrm{T}$ cell exhaustion by multiple inhibitory receptors 
during chronic viral infection. Nat Immunol. (2009) 10:29-37. doi: 10.1038/ ni. 1679

19. Sandalova E, Laccabue D, Boni C, Watanabe T, Tan A, Zong HZ, et al. Increased levels of arginase in patients with acute hepatitis B suppress antiviral T cells. Gastroenterology. (2012) 143:78.e-87.e. doi: 10.1053/j.gastro. 2012.03.041

20. Boettler T, Panther E, Bengsch B, Nazarova N, Spangenberg HC, Blum HE, et al. Expression of the interleukin-7 receptor alpha chain (CD127) on virus-specific $\mathrm{CD} 8+\mathrm{T}$ cells identifies functionally and phenotypically defined memory $\mathrm{T}$ cells during acute resolving hepatitis B virus infection. $J$ Virol. (2006) 80:3532-40. doi: 10.1128/JVI.80.7.3532-3540.2006

21. Zhang Z, Jin B, Zhang J-Y, Xu B, Wang H, Shi M, et al. Dynamic decrease in PD-1 expression correlates with HBV-specific memory CD8 T-cell development in acute self-limited hepatitis B patients. J Hepatol. (2009) 50:1163-73. doi: 10.1016/j.jhep.2009.01.026

22. Zhang Z, Zhang J, Wherry EJ, Jin B, Xu B, Zou Z, et al. Dynamic programmed death 1 expression by virus-specific $\mathrm{CD} 8 \mathrm{~T}$ cells correlates with the outcome of acute hepatitis B. Gastroenterology. (2008) 134:1938.e-49.e. doi: 10.1053/j. gastro.2008.03.037

23. Fisicaro P, Boni C, Barili V, Laccabue D, Ferrari C. Strategies to overcome HBV-specific T cell exhaustion: checkpoint inhibitors and metabolic reprogramming. Curr Opin Virol. (2018) 30:1-8. doi: 10.1016/j.coviro.2018. 01.003

24. Fisicaro P, Valdatta C, Massari M, Loggi E, Biasini E, Sacchelli L, et al. Antiviral intrahepatic T-cell responses can be restored by blocking programmed death-1 pathway in chronic hepatitis B. Gastroenterology. (2010) 138:682.e-93.e. doi: 10.1053/j.gastro.2009.09.052

25. Li H, Wu K, Tao K, Chen L, Zheng Q, Lu X, et al. Tim-3/galectin-9 signaling pathway mediates T-cell dysfunction and predicts poor prognosis in patients with hepatitis B virus-associated hepatocellular carcinoma. Hepatology. (2012) 56:1342-51. doi: 10.1002/hep.25777

26. Huang Z-Y, Xu P, Li J-H, Zeng C-H, Song H-F, Chen H, et al. Clinical significance of dynamics of programmed death ligand-1 expression on circulating CD14 + monocytes and CD19 + B cells with the progression of hepatitis B virus infection. Viral Immunol. (2017) 30:224-31. doi: 10.1089/ vim. 2016.0122

27. Riley JLPD-. 1 signaling in primary T cells. Immunol Rev. (2009) 229:114-25. doi: 10.1111/j.1600-065X.2009.00767.x

28. Yokosuka T, Takamatsu M, Kobayashi-Imanishi W, Hashimoto-Tane A, Azuma M, Saito T. Programmed cell death 1 forms negative costimulatory microclusters that directly inhibit $\mathrm{T}$ cell receptor signaling by recruiting phosphatase SHP2. J Exp Med. (2012) 209:1201-17. doi: 10.1084/jem. 20112741

29. Boussiotis VA. Molecular and biochemical aspects of the PD-1 checkpoint pathway. N Engl J Med. (2016) 375:1767-78. doi: 10.1056/NEJMra1514296

30. Hui E, Cheung J, Zhu J, Su X, Taylor MJ, Wallweber HA, et al. T cell costimulatory receptor $\mathrm{CD} 28$ is a primary target for PD-1-mediated inhibition. Science. (2017) 355:1428-33. doi: 10.1126/science.aaf1292

31. Patsoukis N, Bardhan K, Chatterjee P, Sari D, Liu B, Bell LN, et al. PD-1 alters T-cell metabolic reprogramming by inhibiting glycolysis and promoting lipolysis and fatty acid oxidation. Nat Commun. (2015) 6:6692. doi: 10.1038/ ncomms 7692

32. Boni C, Lampertico P, Talamona L, Giuberti T, Invernizzi F, Barili V, et al. Natural killer cell phenotype modulation and natural killer/T-cell interplay in nucleos(t)ide analogue-treated hepatitis e antigen-negative patients with chronic hepatitis B. Hepatology. (2015) 62:1697-709. doi: 10.1002/hep.28155

33. Lopes AR, Kellam P, Das A, Dunn C, Kwan A, Turner J, et al. Bim-mediated deletion of antigen-specific CD8+ T cells in patients unable to control HBV infection. J Clin Invest. (2008) 118:1835-45. doi: 10.1172/JCI33402

34. Peppa D, Gill US, Reynolds G, Easom NJW, Pallett LJ, Schurich A, et al. Up-regulation of a death receptor renders antiviral $\mathrm{T}$ cells susceptible to NK cell-mediated deletion. J Exp Med. (2013) 210:99-114. doi: 10.1084/jem. 20121172

35. Schurich A, Pallett LJ, Jajbhay D, Wijngaarden J, Otano I, Gill US, et al. Distinct metabolic requirements of exhausted and functional virus-specific CD8 T cells in the same host. Cell Rep. (2016) 16:1243-52. doi: 10.1016/j. celrep.2016.06.078
36. Fisicaro P, Barili V, Montanini B, Acerbi G, Ferracin M, Guerrieri F, et al. Targeting mitochondrial dysfunction can restore antiviral activity of exhausted HBV-specific CD8 T cells in chronic hepatitis B. Nat Med. (2017) 23:327-36. doi: $10.1038 / \mathrm{nm} .4275$

37. Li Y, Tang L, Guo L, Chen C, Gu S, Zhou Y, et al. CXCL13-mediated recruitment of intrahepatic CXCR5+CD8+ T cells favors viral control in chronic HBV infection. J Hepatol. (2019) 72:420-30. doi: 10.1016/j.jhep.2019. 09.031

38. Cheng Y, Zhu YO, Becht E, Aw P, Chen J, Poidinger M, et al. Multifactorial heterogeneity of virus-specific $\mathrm{T}$ cells and association with the progression of human chronic hepatitis B infection. Sci Immunol. (2019) 4:eaau6905. doi: 10.1126/sciimmunol.aau6905

39. Schuch A, Salimi Alizei E, Heim K, Wieland D, Kiraithe MM, Kemming J, et al. Phenotypic and functional differences of HBV core-specific versus HBV polymerase-specific CD8+ T cells in chronically HBV-infected patients with low viral load. Gut. (2019) 68:905-15. doi: 10.1136/gutjnl-2018-316641

40. Hoogeveen RC, Robidoux MP, Schwarz T, Heydmann L, Cheney JA, Kvistad $\mathrm{D}$, et al. Phenotype and function of HBV-specific T cells is determined by the targeted epitope in addition to the stage of infection. Gut. (2019) 68:893-904. doi: 10.1136/gutjnl-2018-316644

41. Huang AC, Postow MA, Orlowski RJ, Mick R, Bengsch B, Manne S, et al. Tcell invigoration to tumour burden ratio associated with anti-PD-1 response. Nature. (2017) 545:60-5. doi: 10.1038/nature22079

42. Utzschneider DT, Charmoy M, Chennupati V, Pousse L, Ferreira DP, Calderon-Copete $\mathrm{S}$, et al. T cell factor 1-expressing memory-like CD8+ T cells sustain the immune response to chronic viral infections. Immunity. (2016) 45:415-27. doi: 10.1016/j.immuni.2016.07.021

43. Im SJ, Hashimoto M, Gerner MY, Lee J, Kissick HT, Burger MC, et al. Defining CD8+ T cells that provide the proliferative burst after PD-1 therapy. Nature. (2016) 537:417-21. doi: 10.1038/nature19330

44. Miller BC, Sen DR, Al Abosy R, Bi K, Virkud YV, LaFleur MW, et al. Subsets of exhausted CD8+ T cells differentially mediate tumor control and respond to checkpoint blockade. Nat Immunol. (2019) 20:326-36. doi: 10. 1038/s41590-019-0312-6

45. Siddiqui I, Schaeuble K, Chennupati V, Fuertes Marraco SA, CalderonCopete S, Pais Ferreira D, et al. Intratumoral Tcf1+PD-1+CD8+ T Cells with Stem-like Properties Promote Tumor Control in Response to Vaccination and Checkpoint Blockade Immunotherapy. Immunity. (2019) 50:195.e211.e. doi: 10.1016/j.immuni.2018.12.021

46. Gide TN, Quek C, Menzies AM, Tasker AT, Shang P, Holst J, et al. Distinct immune cell populations define response to anti-PD-1 monotherapy and anti-PD-1/Anti-CTLA-4 combined therapy. Cancer Cell. (2019) 35:238.e55.e. doi: 10.1016/j.ccell.2019.01.003

47. Park J, Wong DK, Wahed AS, Lee WM, Feld JJ, Terrault N, et al. HBV-specific and global T-cell dysfunction in chronic hepatitis B. Gastroenterology. (2017) 150:684-95. doi: 10.1053/j.gastro.2015.11.050.HBV-specific

48. Jacobi FJ, Wild K, Smits M, Zoldan K, Csernalabics B, Flecken T, et al. OX40 stimulation and PD-L1 blockade synergistically augment HBV-specific CD4 T cells in patients with HBeAg-negative infection. J Hepatol. (2019) 70:1103-13. doi: 10.1016/j.jhep.2019.02.016

49. Salimzadeh L, Le Bert N, Dutertre C-A, Gill US, Newell EW, Frey C, et al. PD-1 blockade partially recovers dysfunctional virus-specific B cells in chronic hepatitis B infection. J Clin Invest. (2018) 128:4573-87. doi: 10.1172/ JCI121957

50. Burton AR, Pallett LJ, McCoy LE, Suveizdyte K, Amin OE, Swadling L, et al. Circulating and intrahepatic antiviral B cells are defective in hepatitis B. J Clin Invest. (2018) 128:4588-603. doi: 10.1172/JCI121960

51. Larkin J, Chiarion-Sileni V, Gonzalez R, Grob JJ, Cowey CL, Lao CD, et al. Combined nivolumab and ipilimumab or monotherapy in untreated melanoma. N Engl J Med. (2015) 373:23-34. doi: 10.1056/NEJMoa1504030

52. Hao C, Tian J, Liu H, Li F, Niu H, Zhu B. Efficacy and safety of anti-PD-1 and anti-PD-1 combined with anti-CTLA-4 immunotherapy to advanced melanoma. Medicine (Baltimore). (2017) 96:e7325. doi: 10.1097/ MD.0000000000007325

53. Chowdhury PS, Chamoto K, Honjo T. Combination therapy strategies for improving PD-1 blockade efficacy: a new era in cancer immunotherapy. $J$ Intern Med. (2018) 283:110-20. doi: 10.1111/joim.12708 
54. Shah NJ, Al-Shbool G, Blackburn M, Cook M, Kelly WJ, Belouali A, et al. Safety and efficacy of immune checkpoint inhibitors (ICIs) in patients with HIV, hepatitis B, or hepatitis C viral infections. In: Proceedings of the American Association for Cancer Research Annual Meeting 2019. Philadelphia (PA): American Association for Cancer Research (2019). doi: 10.1158/15387445.SABCS18-3230

55. Das A, Hoare M, Davies N, Lopes AR, Dunn C, Kennedy PTF, et al. Functional skewing of the global CD8 T cell population in chronic hepatitis B virus infection. J Exp Med. (2008) 205:2111-24. doi: 10.1084/jem.20072076

56. Wieland S, Thimme R, Purcell RH, Chisari FV. Genomic analysis of the host response to hepatitis B virus infection. Proc Natl Acad Sci USA. (2004) 101:6669-74. doi: 10.1073/pnas.0401771101

57. Chang K-M, Traum D, Park J-J, Ho S, Ojiro K, Wong DK, et al. Distinct phenotype and function of circulating V $\delta 1+$ and V $\delta 2+\gamma \delta \mathrm{T}$-cells in acute and chronic hepatitis B. PLoS Pathog. (2019) 15:e1007715. doi: 10.1371/journal. ppat. 1007715

58. Lai Q, Ma S, Ge J, Huang Z, Huang X, Jiang X, et al. TCR $\gamma \delta+C D 4-C D 8-T$ cells suppress the CD8+ T-cell response to hepatitis $B$ virus peptides, and are associated with viral control in chronic hepatitis B. PLoS One. (2014) 9:e88475. doi: 10.1371/journal.pone.0088475

59. Wu X, Zhang J-Y, Huang A, Li Y-Y, Zhang S, Wei J, et al. Decreased V $\delta 2$ $\gamma \delta \mathrm{T}$ cells associated with liver damage by regulation of Th17 response in patients with chronic hepatitis B. J Infect Dis. (2013) 208:1294-304. doi: 10.1093/infdis/jit312

60. Chen M, Zhang D, Zhen W, Shi Q, Liu Y, Ling N, et al. Characteristics of circulating $\mathrm{T}$ cell receptor $\gamma \delta \mathrm{T}$ cells from individuals chronically infected with hepatitis B virus (HBV): an association between $\mathrm{V} \delta 2$ subtype and chronic HBV infection. J Infect Dis. (2008) 198:1643-50. doi: 10.1086/593065

61. Conroy MJ, Mac Nicholas R, Taylor M, O’Dea S, Mulcahy F, Norris S, et al. Increased frequencies of circulating IFN- $\gamma$-producing $\mathrm{V} \delta 1+$ and $\mathrm{V} \delta 2+\gamma \delta$ $\mathrm{T}$ cells in patients with asymptomatic persistent hepatitis $\mathrm{B}$ virus infection. Viral Immunol. (2015) 28:201-8. doi: 10.1089/vim.2014.0133

62. Kosinska AD, Liu J, Lu M, Roggendorf M. Therapeutic vaccination and immunomodulation in the treatment of chronic hepatitis B: preclinical studies in the woodchuck. Med Microbiol Immunol. (2015) 204:103-14. doi: 10.1007/s00430-014-0379-5

63. Balsitis S, Gali V, Mason PJ, Chaniewski S, Levine SM, Wichroski MJ, et al. Safety and efficacy of anti-PD-L1 therapy in the woodchuck model of HBV infection. PLoS One. (2018) 13:e0190058. doi: 10.1371/journal.pone.0190058

64. Gane E, Verdon DJ, Brooks AE, Gaggar A, Nguyen AH, Subramanian GM, et al. Anti-PD-1 blockade with nivolumab with and without therapeutic vaccination for virally suppressed chronic hepatitis B: A pilot study. J Hepatol. (2019) 71:900-7. doi: 10.1016/j.jhep.2019.06.028

65. Pauken KE, Sammons MA, Odorizzi PM, Manne S, Godec J, Khan O, et al. Epigenetic stability of exhausted T cells limits durability of reinvigoration by PD-1 blockade. Science. (2016) 354:1160-5. doi: 10.1126/science.aaf2807

66. Ghoneim HE, Fan Y, Moustaki A, Abdelsamed HA, Dash P, Dogra P, et al. De novo epigenetic programs inhibit PD-1 blockade-mediated T cell rejuvenation. Cell. (2017) 170:142.e-57.e. doi: 10.1016/j.cell.2017.06.007

67. Gehring AJ, Sun D, Kennedy PTF, Nolte-'t Hoen E, Lim SG, Wasser S, et al. The Level of Viral Antigen Presented by Hepatocytes Influences CD8 T-Cell Function. J Virol. (2007) 81:2940-9. doi: 10.1128/JVI.02415-06

68. Ojiro K, Qu X, Cho H, Park J, Jakobsen BK, Kaplan DE, et al. Modulation of hepatitis $\mathrm{C}$ virus-specific $\mathrm{CD} 8$ effector T-cell function with antiviral effect in infectious hepatitis c virus coculture model. J Virol. (2017) 91:e2129-2116. doi: 10.1128/JVI.02129-16

69. Jo J, Aichele U, Kersting N, Klein R, Aichele P, Bisse E, et al. Analysis of CD8+ T-cell-mediated inhibition of hepatitis $\mathrm{C}$ virus replication using a novel immunological model. Gastroenterology. (2009) 136:1391-401. doi: 10.1053/j.gastro.2008.12.034

70. Wong YC, Tay SS, McCaughan GW, Bowen DG, Bertolino P. Immune outcomes in the liver: Is CD8 T cell fate determined by the environment? J Hepatol. (2015) 63:1005-14. doi: 10.1016/j.jhep.2015.05.033

71. Tay SS, Wong YC, McDonald DM, Wood NAW, Roediger B, Sierro F, et al. Antigen expression level threshold tunes the fate of CD8 T cells during primary hepatic immune responses. Proc Natl Acad Sci USA. (2014) 111:E2540-9. doi: 10.1073/pnas.1406674111
72. Isogawa M, Chung J, Murata Y, Kakimi K, Chisari FV. CD40 Activation Rescues Antiviral CD8+ T Cells from PD-1-Mediated Exhaustion. PLoS Pathog. (2013) 9:e1003490. doi: 10.1371/journal.ppat.1003490

73. Isogawa M, Furuichi Y, Chisari FV. Oscillating CD8+ T cell effector functions after antigen recognition in the liver. Immunity. (2005) 23:53-63. doi: 10. 1016/j.immuni.2005.05.005

74. Bénéchet AP, De Simone G, Di Lucia P, Cilenti F, Barbiera G, Le Bert N, et al. Dynamics and genomic landscape of $\mathrm{CD} 8+\mathrm{T}$ cells undergoing hepatic priming. Nature. (2019) 574:200-5. doi: 10.1038/s41586-019-1620-6

75. Backes S, Jäger $C$, Dembek CJ, Kosinska $A D$, Bauer T, Stephan A-S, et al. Protein-prime/modified vaccinia virus Ankara vector-boost vaccination overcomes tolerance in high-antigenemic HBV-transgenic mice. Vaccine. (2016) 34:923-32. doi: 10.1016/j.vaccine.2015.12.060

76. Michler T, Kosinska AD, Festag J, Bunse T, Su J, Ringelhan M, et al. Knockdown of virus antigen expression increases therapeutic vaccine efficacy in high-titer hepatitis B virus carrier mice. Gastroenterology. (2020). doi: 10.1053/j.gastro.2020.01.032 [Epub ahead of print].

77. Boni C, Laccabue D, Lampertico P, Giuberti T, Viganò M, Schivazappa S, et al. Restored function of HBV-specific T cells after long-term effective therapy with nucleos(t)ide analogues. Gastroenterology. (2012) 143:963.e-73.e. doi: 10.1053/j.gastro.2012.07.014

78. Boni C, Barili V, Acerbi G, Rossi M, Vecchi A, Laccabue D, et al. Immunetherapy: from molecular mechanisms to clinical applications. Int J Mol Sci. (2019) 20:2754. doi: 10.3390/ijms20112754

79. Grakoui A, Crispe IN. Presentation of hepatocellular antigens. Cell Mol Immunol. (2016) 13:293-300. doi: 10.1038/cmi.2015.109

80. Horst AK, Neumann K, Diehl L, Tiegs G. Modulation of liver tolerance by conventional and nonconventional antigen-presenting cells and regulatory immune cells. Cell Mol Immunol. (2016) 13:277-92. doi: 10.1038/cmi. 2015.112

81. Dou L, Ono Y, Chen Y, Thomson A, Chen X. Hepatic dendritic cells, the tolerogenic liver environment, and liver disease. Semin Liver Dis. (2018) 38:170-80. doi: 10.1055/s-0038-1646949

82. De Creus A, Abe M, Lau AH, Hackstein H, Raimondi G, Thomson AW. Low TLR4 expression by liver dendritic cells correlates with reduced capacity to activate allogeneic $\mathrm{t}$ cells in response to endotoxin. J Immunol. (2005) 174:2037-45. doi: 10.4049/jimmunol.174.4.2037

83. Abdullah Z, Knolle PA. Liver macrophages in healthy and diseased liver. Pflügers Arch Eur J Physiol. (2017) 469:553-60. doi: 10.1007/s00424-0171954-6

84. Knolle PA, Wohlleber D. Immunological functions of liver sinusoidal endothelial cells. Cell Mol Immunol. (2016) 13:347-53. doi: 10.1038/cmi. 2016.5

85. Schildberg FA, Sharpe AH, Turley SJ. Hepatic immune regulation by stromal cells. Curr Opin Immunol. (2015) 32:1-6. doi: 10.1016/j.coi.2014.10.002

86. Lohse A, Knolle P, Bilo K, Uhrig A, Waldmann C, Ibe M, et al. Antigenpresenting function and B7 expression of murine sinusoidal endothelial cells and Kupffer cells. Gastroenterology. (1996) 110:1175-81. doi: 10.1053/gast. 1996.v110.pm8613007

87. Diehl L, Schurich A, Grochtmann R, Hegenbarth S, Chen L, Knolle PA. Tolerogenic maturation of liver sinusoidal endothelial cells promotes B7homolog 1-dependent CD8+ T cell tolerance. Hepatology. (2007) 47:296-305. doi: 10.1002/hep.21965

88. You Q, Cheng L, Kedl RM, Ju C. Mechanism of T cell tolerance induction by murine hepatic Kupffer cells. Hepatology. (2008) 48:978-90. doi: 10.1002/ hep. 22395

89. Uchikura K, Wada T, Hoshino S, Nagakawa Y, Aiko T, Bulkley GB, et al. Lipopolysaccharides induced increases in Fas ligand expression by Kupffer cells via mechanisms dependent on reactive oxygen species. Am J Physiol Liver Physiol. (2004) 287:G620-6. doi: 10.1152/ajpgi.00314.2003

90. Mehrfeld C, Zenner S, Kornek M, Lukacs-Kornek V. The contribution of non-professional antigen-presenting cells to immunity and tolerance in the liver. Front Immunol. (2018) 9:635. doi: 10.3389/fimmu.2018.00635

91. Yu M-C, Chen C-H, Liang X, Wang L, Gandhi CR, Fung JJ, et al. Inhibition of T-cell responses by hepatic stellate cells via B7-H1-mediated T-cell apoptosis in mice. Hepatology. (2004) 40:1312-21. doi: 10.1002/hep. 20488 
92. Chinnadurai R, Grakoui A. B7-H4 mediates inhibition of T cell responses by activated murine hepatic stellate cells. Hepatology. (2010) 52:2177-85. doi: 10.1002/hep. 23953

93. Charles R, Chou H-S, Wang L, Fung JJ, Lu L, Qian S. Human Hepatic Stellate Cells Inhibit T-Cell Response Through B7-H1 Pathway. Transplant J. (2013) 96:17-24. doi: 10.1097/TP.0b013e318294caae

94. Holz LE, Benseler V, Bowen DG, Bouillet P, Strasser A, O'Reilly L, et al. Intrahepatic murine CD8 T-cell activation associates with a distinct phenotype leading to bim-dependent death. Gastroenterology. (2008) 135:989-97. doi: 10.1053/j.gastro.2008.05.078

95. Schildberg FA, Wojtalla A, Siegmund SV, Endl E, Diehl L, Abdullah Z, et al. Murine hepatic stellate cells veto CD8 T cell activation by a CD54-dependent mechanism. Hepatology. (2011) 54:262-72. doi: 10.1002/hep.24352

96. Doherty DG. Immunity, tolerance and autoimmunity in the liver: a comprehensive review. J Autoimmun. (2016) 66:60-75. doi: 10.1016/j.jaut. 2015.08.020

97. Perez RV, Swanson C, Morgan M, Erickson K, Hubbard NE, German JB. Portal venous transfusion up-regulates Kupffer cell cyclooxygenase activity: a mechanism of immunosuppression in organ transplantation. Transplantation. (1997) 64:135-9. doi: 10.1097/00007890-199707150-00023

98. Yan M-L. Inhibition of allogeneic T-cell response by kupffer cells expressing indoleamine 2,3-dioxygenase. World J Gastroenterol. (2010) 16:636. doi: 10. 3748/wjg.v16.i5.636

99. Knolle U, Loser H, Lohse SG. IL-10 down-regulates $\mathrm{T}$ cell activation by antigen-presenting liver sinusoidal endothelial cells through decreased antigen uptake via the mannose receptor and lowered surface expression of accessory molecules. Clin Exp Immunol. (1998) 114:427-33. doi: 10.1046/j. 1365-2249.1998.00713.x

100. Bissell DM, Wang SS, Jarnagin WR, Roll FJ. Cell-specific expression of transforming growth factor-beta in rat liver. Evidence for autocrine regulation of hepatocyte proliferation. . J Clin Invest. (1995) 96:447-55. doi: 10.1172/JCI118055

101. Castellaneta A, Sumpter TL, Chen L, Tokita D, Thomson AW. NOD2 Ligation Subverts IFN- $\alpha$ Production by Liver Plasmacytoid Dendritic Cells and Inhibits Their T Cell Allostimulatory Activity via B7-H1 Up-Regulation. J Immunol. (2009) 183:6922-32. doi: 10.4049/jimmunol.0900582

102. Soysa R, Wu X, Crispe IN. Dendritic cells in hepatitis and liver transplantation. Liver Transplant. (2017) 23:1433-9. doi: 10.1002/lt.24833

103. Kelly A, Fahey R, Fletcher JM, Keogh C, Carroll AG, Siddachari R, et al. CD141+ myeloid dendritic cells are enriched in healthy human liver. $J$ Hepatol. (2014) 60:135-42. doi: 10.1016/j.jhep.2013.08.007

104. Manavalan JS, Rossi PC, Vlad G, Piazza F, Yarilina A, Cortesini R, et al. High expression of ILT3 and ILT4 is a general feature of tolerogenic dendritic cells. Transpl Immunol. (2003) 11:245-58. doi: 10.1016/S0966-3274(03)00058-3

105. Chang CC, Ciubotariu R, Manavalan JS, Yuan J, Colovai AI, Piazza F, et al. Tolerization of dendritic cells by TS cells: the crucial role of inhibitory receptors ILT3 and ILT4. Nat Immunol. (2002) 3:237-43. doi: 10.1038/ni760

106. Yonejima A, Mizukoshi E, Tamai T, Nakagawa H, Kitahara M, Yamashita $\mathrm{T}$, et al. Characteristics of impaired dendritic cell function in patients with hepatitis B virus infection. Hepatology. (2019) 70:25-39. doi: 10.1002/hep. 30637

107. Woltman AM, Boonstra A, Janssen HLA. Dendritic cells in chronic viral hepatitis B and C: victims or guardian angels? Gut. (2010) 59:115-25. doi: 10.1136/gut.2009.181040

108. van Montfoort $\mathrm{N}$, van der Aa E, van den Bosch A, Brouwers $H$, Vanwolleghem T, Janssen HLA, et al. Hepatitis B virus surface antigen activates myeloid dendritic cells via a soluble CD14-dependent mechanism. J Virol. (2016) 90:6187-99. doi: 10.1128/JVI.02903-15

109. Li M, Zhou Z-H, Sun X-H, Zhang X, Zhu X-J, Jin S-G, et al. Hepatitis B core antigen upregulates $\mathrm{B} 7-\mathrm{H} 1$ on dendritic cells by activating the AKT/ERK/P38 pathway: a possible mechanism of hepatitis B virus persistence. Lab Investig. (2016) 96:1156-64. doi: 10.1038/labinvest.2016.96

110. van der Aa E, Buschow SI, Biesta PJ, Janssen HLA, Woltman AM. The effect of chronic hepatitis B virus infection on BDCA3+ dendritic cell frequency and function. PLoS One. (2016) 11:e0161235. doi: 10.1371/journal.pone. 0161235

111. Woltman AM, Op den Brouw ML, Biesta PJ, Shi CC, Janssen HLA. Hepatitis $\mathrm{B}$ virus lacks immune activating capacity, but actively inhibits plasmacytoid dendritic cell function. PLoS One. (2011) 6:e15324. doi: 10.1371/journal. pone.0015324

112. Xu Y, Hu Y, Shi B, Zhang X, Wang J, Zhang Z, et al. HBsAg inhibits TLR9mediated activation and IFN- $\alpha$ production in plasmacytoid dendritic cells. Mol Immunol. (2009) 46:2640-6. doi: 10.1016/j.molimm.2009.04.031

113. Gehring AJ, Ann D, Angelo J. Dissecting the dendritic cell controversy in chronic hepatitis B virus infection. Cell Mol Immunol. (2015) 12:283-91. doi: $10.1038 / \mathrm{cmi} .2014 .95$

114. Gehring AJ, Haniffa M, Kennedy PT, Ho ZZ, Boni C, Shin A, et al. Mobilizing monocytes to cross-present circulating viral antigen in chronic infection. $J$ Clin Invest. (2013) 123:3766-76. doi: 10.1172/JCI66043

115. Tavakoli S, Mederacke I, Herzog-Hauff S, Glebe D, Grün S, Strand D, et al. Peripheral blood dendritic cells are phenotypically and functionally intact in chronic hepatitis B virus (HBV) infection. Clin Exp Immunol. (2007) 151:61-70. doi: 10.1111/j.1365-2249.2007.03547.x

116. Diao H, Cui G, Chen J, He J, Lu C, Wei Y, et al. Osteopontin promotes dendritic cell maturation and function in response to HBV antigens. Drug Des Devel Ther. (2015) 9:3003-16. doi: 10.2147/DDDT.S81656

117. Xie Q, Shen H-C, Jia N-N, Wang H, Lin L-Y, An B-Y, et al. Patients with chronic hepatitis $\mathrm{B}$ infection display deficiency of plasmacytoid dendritic cells with reduced expression of TLR9. Microbes Infect. (2009) 11:515-23. doi: 10.1016/j.micinf.2009.02.008

118. Ouaguia L, Leroy V, Dufeu-Duchesne T, Durantel D, Decaens T, Hubert M, et al. Circulating and hepatic BDCA1+, BDCA2+, and BDCA3+ dendritic cells are differentially subverted in patients with chronic HBV infection. Front Immunol. (2019) 10:112. doi: 10.3389/fimmu.2019.00112

119. Faure-Dupuy S, Lucifora J, Durantel D. Interplay between the hepatitis B virus and innate immunity: from an understanding to the development of therapeutic concepts. Viruses. (2017) 9:95. doi: 10.3390/v9050095

120. Xu N, Yao H-P, Lv G-C, Chen Z. Downregulation of TLR7/9 leads to deficient production of IFN- $\alpha$ from plasmacytoid dendritic cells in chronic hepatitis B. Inflamm Res. (2012) 61:997-1004. doi: 10.1007/s00011-012-0493-Z

121. Martinet J, Dufeu-Duchesne T, Bruder Costa J, Larrat S, Marlu A, Leroy V, et al. Altered Functions of Plasmacytoid Dendritic Cells and Reduced Cytolytic Activity of Natural Killer Cells in Patients With Chronic HBV Infection. Gastroenterology. (2012) 143:1586.e-96.e. doi: 10.1053/j.gastro. 2012.08.046

122. Vincent IE, Zannetti C, Lucifora J, Norder H, Protzer U, Hainaut P, et al. Hepatitis B virus impairs TLR9 expression and function in plasmacytoid dendritic cells. PLoS One. (2011) 6:e26315. doi: 10.1371/journal.pone. 0026315

123. Shi B, Ren G, Hu Y, Wang S, Zhang Z, Yuan Z. HBsAg inhibits IFN$\alpha$ production in plasmacytoid dendritic cells through TNF- $\alpha$ and IL-10 induction in monocytes. PLoS One. (2012) 7:e44900. doi: 10.1371/journal. pone.0044900

124. Wu L, Peng W, Wu H, Miaw S, Yeh S, Yang H, et al. Lymphocyte antigen 6 complex, Locus $\mathrm{C}+$ monocytes and kupffer cells orchestrate liver immune responses against hepatitis B virus in mice. Hepatology. (2019) 69:2364-80. doi: 10.1002/hep.30510

125. Locati M, Curtale G, Mantovani A. Diversity, mechanisms, and significance of macrophage plasticity. Annu Rev Pathol Mech Dis. (2020) 15:421057329. doi: 10.1146/annurev-pathmechdis-012418-012718

126. Bility MT, Cheng L, Zhang Z, Luan Y, Li F, Chi L, et al. Hepatitis B virus infection and immunopathogenesis in a humanized mouse model: induction of human-specific liver fibrosis and M2-like macrophages. PLoS Pathog. (2014) 10:e1004032. doi: 10.1371/journal.ppat.1004032

127. Kuchroo VK, Prabhu Das M, Brown JA, Ranger AM, Zamvil SS, Sobel RA, et al. B7-1 and B7-2 costimulatory molecules activate differentially the Th1/Th2 developmental pathways: Application to autoimmune disease therapy. Cell. (1995) 80:707-18. doi: 10.1016/0092-8674(95)9 0349-6

128. Said EA, Al-Reesi I, Al-Riyami M, Al-Naamani K, Al-Sinawi S, Al-Balushi MS, et al. Increased CD86 but Not CD80 and PD-L1 Expression on Liver CD68+ Cells during Chronic HBV Infection. PLoS One. (2016) 11:e0158265. doi: 10.1371/journal.pone.0158265

129. Boltjes A, van Montfoort N, Biesta PJ, Op den Brouw ML, Kwekkeboom J, van der Laan LJW, et al. Kupffer cells interact with hepatitis B surface antigen in vivo and in vitro, leading to proinflammatory cytokine production and 
natural killer cell function. J Infect Dis. (2015) 211:1268-78. doi: 10.1093/ infdis/jiu599

130. Li H, Zheng H-W, Chen H, Xing Z-Z, You H, Cong M, et al. Hepatitis B virus particles preferably induce Kupffer cells to produce TGF- $\beta 1$ over proinflammatory cytokines. Dig Liver Dis. (2012) 44:328-33. doi: 10.1016/j.dld. 2011.11.005

131. Li M, Sun R, Xu L, Yin W, Chen Y, Zheng X, et al. Kupffer cells support hepatitis B virus-mediated CD8 $+\mathrm{T}$ cell exhaustion via hepatitis B core antigen-TLR2 interactions in mice. J Immunol. (2015) 195:3100-9. doi: 10. 4049/jimmunol.1500839

132. Liu J, Yu Q, Wu W, Huang X, Broering R, Werner M, et al. TLR2 Stimulation Strengthens Intrahepatic Myeloid-Derived Cell-Mediated T Cell Tolerance through Inducing Kupffer Cell Expansion and IL-10 Production. J Immunol. (2018) 200:2341-51. doi: 10.4049/jimmunol.1700540

133. Faure-Dupuy S, Delphin M, Aillot L, Dimier L, Lebossé F, Fresquet J, et al. Hepatitis B virus-induced modulation of liver macrophage function promotes hepatocyte infection. J Hepatol. (2019) 71:1086-98. doi: 10.1016/ j.jhep.2019.06.032

134. Polakos NK, Cornejo JC, Murray DA, Wright KO, Treanor JJ, Crispe IN, et al. Kupffer cell-dependent hepatitis occurs during influenza infection. Am J Pathol. (2006) 168:1169-78. doi: 10.2353/ajpath.2006.050875

135. Ibrahim J, Nguyen AH, Rehman A, Ochi A, Jamal M, Graffeo CS, et al. Dendritic cell populations with different concentrations of lipid regulate tolerance and immunity in mouse and human liver. Gastroenterology. (2012) 143:1061-72. doi: 10.1053/j.gastro.2012.06.003

136. Suslov A, Boldanova T, Wang X, Wieland S, Heim MH. Hepatitis B Virus Does Not Interfere With Innate Immune Responses in the Human Liver. Gastroenterology. (2018) 154:1778-90. doi: 10.1053/j.gastro.2018.01.034

137. Luangsay S, Ait-Goughoulte M, Michelet M, Floriot O, Bonnin M, Gruffaz M, et al. Expression and functionality of Toll- and RIG-like receptors in HepaRG cells. J Hepatol. (2015) 63:1077-85. doi: 10.1016/j.jhep.2015.06.022

138. Martinet J, Leroy V, Dufeu-Duchesne T, Larrat S, Richard M-J, Zoulim F, et al. Plasmacytoid dendritic cells induce efficient stimulation of antiviral immunity in the context of chronic hepatitis B virus infection. Hepatology. (2012) 56:1706-18. doi: 10.1002/hep.25879

139. Volckmar J, Gereke M, Ebensen T, Riese P, Philipsen L, Lienenklaus S, et al. Targeted antigen delivery to dendritic cells elicits robust antiviral $\mathrm{T}$ cell-mediated immunity in the liver. Sci Rep. (2017) 7:43985. doi: 10.1038/ srep 43985

140. Hassannia H, Ghasemi Chaleshtari M, Atyabi F, Nosouhian M, Masjedi A, Hojjat-Farsangi M, et al. Blockage of immune checkpoint molecules increases $\mathrm{T}$-cell priming potential of dendritic cell vaccine. Immunology. (2020) 159:75-87. doi: 10.1111/imm.13126

141. Knolle PA, Thimme R. Hepatic immune regulation and its involvement in viral hepatitis infection. Gastroenterology. (2014) 146:1193-207. doi: 10.1053/ j.gastro.2013.12.036

142. Terness P, Bauer TM, Röse L, Dufter C, Watzlik A, Simon H, et al. Inhibition of allogeneic $\mathrm{T}$ cell proliferation by indoleamine 2,3-dioxygenase-expressing dendritic cells. J Exp Med. (2002) 196:447-57. doi: 10.1084/jem.20020052

143. Dai H, Dai Z. The role of tryptophan catabolism in acquisition and effector function of memory T cells. Curr Opin Organ Transplant. (2008) 13:31-5. doi: 10.1097/MOT.0b013e3282f3dee1

144. Badawy AAB. Kynurenine pathway of tryptophan metabolism: regulatory and functional aspects. Int J Tryptophan Res. (2017) 10:117864691769193. doi: $10.1177 / 1178646917691938$

145. Chiesa MD, Carlomagno S, Frumento G, Balsamo M, Cantoni C, Conte R, et al. The tryptophan catabolite l-kynurenine inhibits the surface expression of NKp46- and NKG2D-activating receptors and regulates NK-cell function. Blood. (2006) 108:4118-25. doi: 10.1182/blood-2006-03-006700

146. Protzer U, Maini MK, Knolle PA. Living in the liver: hepatic infections. Nat Rev Immunol. (2012) 12:201-13. doi: 10.1038/nri3169

147. Munder M. Suppression of T-cell functions by human granulocyte arginase. Blood. (2006) 108:1627-34. doi: 10.1182/blood-2006-11-010389

148. Pallett LJ, Gill US, Quaglia A, Sinclair LV, Jover-Cobos M, Schurich A, et al. Metabolic regulation of hepatitis B immunopathology by myeloid-derived suppressor cells. Nat Med. (2015) 21:591-600. doi: 10.1038/nm.3856

149. Höchst B, Schildberg FA, Sauerborn P, Gäbel YA, Gevensleben H, Goltz $\mathrm{D}$, et al. Activated human hepatic stellate cells induce myeloid derived suppressor cells from peripheral blood monocytes in a CD44-dependent fashion. J Hepatol. (2013) 59:528-35. doi: 10.1016/j.jhep.2013.04.033

150. Hammerich L, Tacke F. Emerging roles of myeloid derived suppressor cells in hepatic inflammation and fibrosis. World J Gastrointest Pathophysiol. (2015) 6:43. doi: 10.4291/wjgp.v6.i3.43

151. Zhang H, Lian M, Zhang J, Bian Z, Tang R, Miao Q, et al. A functional characteristic of cysteine-rich protein 61: Modulation of myeloid-derived suppressor cells in liver inflammation. Hepatology. (2018) 67:232-46. doi: 10.1002/hep. 29418

152. Pal S, Nandi M, Dey D, Chakraborty BC, Shil A, Ghosh S, et al. Myeloidderived suppressor cells induce regulatory T cells in chronically HBV infected patients with high levels of hepatitis B surface antigen and persist after antiviral therapy. Aliment Pharmacol Ther. (2019) 49:1346-59. doi: 10.1111/ apt.15226

153. Zeng Y, Li Y, Xu Z, Gan W, Lu L, Huang X, et al. Myeloid-derived suppressor cells expansion is closely associated with disease severity and progression in HBV-related acute-on-chronic liver failure. J Med Virol. (2019) 91:1510-8. doi: $10.1002 / j m v .25466$

154. Huang L-R, Wohlleber D, Reisinger F, Jenne CN, Cheng R-L, Abdullah Z, et al. Intrahepatic myeloid-cell aggregates enable local proliferation of CD8+ $\mathrm{T}$ cells and successful immunotherapy against chronic viral liver infection. Nat Immunol. (2013) 14:574-83. doi: 10.1038/ni.2573

155. Lin YC, Hsu CY, Huang SK, Fan YH, Huang CH, Yang CK, et al. Induction of liver-specific intrahepatic myeloid cells aggregation expands CD8 T cell and inhibits growth of murine hepatoma. Oncoimmunology. (2018) 7:1-12. doi: 10.1080/2162402X.2018.1502129

156. Weston CJ, Zimmermann HW, Adams DH. The role of myeloid-derived cells in the progression of liver disease. Front Immunol. (2019) 10:1-20. doi: 10.3389/fimmu.2019.00893

157. Sumpter TL, Dangi A, Matta BM, Huang C, Stolz DB, Vodovotz Y, et al. Hepatic stellate cells undermine the allostimulatory function of liver myeloid dendritic cells via STAT3-dependent induction of IDO. J Immunol. (2012) 189:3848-58. doi: 10.4049/jimmunol.1200819

158. Matta BM, Raimondi G, Rosborough BR, Sumpter TL, Thomson AWIL-. 27 Production and STAT3-dependent upregulation of B7-H1 mediate immune regulatory functions of liver plasmacytoid dendritic cells. J Immunol. (2012) 188:5227-37. doi: 10.4049/jimmunol.1103382

159. Ito $\mathrm{T}$, Yang $\mathrm{M}$, Wang $\mathrm{Y}-\mathrm{H}$, Lande $\mathrm{R}$, Gregorio J, Perng OA, et al. Plasmacytoid dendritic cells prime IL-10-producing T regulatory cells by inducible costimulator ligand. J Exp Med. (2007) 204:105-15. doi: 10.1084/ jem. 20061660

160. Mascanfroni ID, Yeste A, Vieira SM, Burns EJ, Patel B, Sloma I, et al. IL-27 acts on DCs to suppress the T cell response and autoimmunity by inducing expression of the immunoregulatory molecule CD39. Nat Immunol. (2013) 14:1054-63. doi: 10.1038/ni.2695

161. Crispe IN. Immune tolerance in liver disease. Hepatology. (2014) 60:2109-17. doi: 10.1002/hep.27254

162. Favre D, Mold J, Hunt PW, Kanwar B, Loke P, Seu L, et al. Tryptophan catabolism by indoleamine 2,3-dioxygenase 1 alters the balance of TH17 to regulatory T cells in HIV disease. Sci Transl Med. (2010) 2:ra36-32. doi: 10.1126/scitranslmed.3000632

163. Higashitani K, Kanto T, Kuroda S, Yoshio S, Matsubara T, Kakita N, et al. Association of enhanced activity of indoleamine 2,3-dioxygenase in dendritic cells with the induction of regulatory $\mathrm{T}$ cells in chronic hepatitis C infection. J Gastroenterol. (2013) 48:660-70. doi: 10.1007/s00535-0120667-z

164. Marinelarena A, Bhattacharya P, Kumar P, Maker AV, Prabhakar BS. Identification of a novel OX40L+ dendritic cell subset that selectively expands regulatory T cells. Sci Rep. (2018) 8:14940. doi: 10.1038/s41598-018-33 $307-\mathrm{z}$

165. Carambia A, Freund B, Schwinge D, Heine M, Laschtowitz A, Huber S, et al. TGF- $\beta$-dependent induction of CD4+CD25+Foxp3+ Tregs by liver sinusoidal endothelial cells. J Hepatol. (2014) 61:594-9. doi: 10.1016/j.jhep. 2014.04.027

166. Böttcher JP, Schanz O, Wohlleber D, Abdullah Z, Debey-Pascher S, Staratschek-Jox A, et al. Liver-primed memory $\mathrm{T}$ cells generated under noninflammatory conditions provide anti-infectious immunity. Cell Rep. (2013) 3:779-95. doi: 10.1016/j.celrep.2013.02.008 
167. Ichikawa S, Mucida D, Tyznik AJ, Kronenberg M, Cheroutre H. Hepatic stellate cells function as regulatory bystanders. J Immunol. (2011) 186:554955. doi: 10.4049/jimmunol.1003917

168. Friedman SL. Hepatic stellate cells: protean. multifunctional, and enigmatic cells of the liver. Physiol Rev. (2008) 88:125-72. doi: 10.1152/physrev.00013. 2007

169. Dunham RM, Thapa M, Velazquez VM, Elrod EJ, Denning TL, Pulendran $\mathrm{B}$, et al. Hepatic stellate cells preferentially induce Foxp3 + regulatory $\mathrm{T}$ cells by production of retinoic acid. J Immunol. (2013) 190:2009-16. doi: 10.4049/jimmunol.1201937

170. Li X, Su Y, Hua X, Xie C, Liu J, Huang Y, et al. Levels of hepatic Th17 cells and regulatory $\mathrm{T}$ cells upregulated by hepatic stellate cells in advanced HBVrelated liver fibrosis. J Transl Med. (2017) 15:75. doi: 10.1186/s12967-017$1167-y$

171. Waggoner SN, Cornberg M, Selin LK, Welsh RM. Natural killer cells act as rheostats modulating antiviral T cells. Nature. (2012) 481:394-8. doi: 10. 1038/nature10624

172. Lang PA, Lang KS, Xu HC, Grusdat M, Parish IA, Recher M, et al. Natural killer cell activation enhances immune pathology and promotes chronic infection by limiting CD8+ T-cell immunity. Proc Natl Acad Sci USA. (2012) 109:1210-5. doi: 10.1073/pnas.1118834109

173. Zingoni A, Ardolino M, Santoni A, Cerboni C. NKG2D and DNAM-1 activating receptors and their ligands in NK-T cell interactions: role in the NK cell-mediated negative regulation of T cell responses. Front Immunol. (2013) 3:408. doi: 10.3389/fimmu.2012.00408

174. Crouse J, Xu HC, Lang PA, Oxenius ANK. cells regulating T cell responses: mechanisms and outcome. Trends Immunol. (2015) 36:49-58. doi: 10.1016/j. it.2014.11.001

175. Cerboni C, Zingoni A, Cippitelli M, Piccoli M, Frati L, Santoni A. Antigenactivated human $\mathrm{T}$ lymphocytes express cell-surface NKG2D ligands via an ATM/ATR-dependent mechanism and become susceptible to autologous NK- cell lysis. Blood. (2007) 110:606-15. doi: 10.1182/blood-2006-10-05 2720

176. Crouse J, Bedenikovic G, Wiesel M, Ibberson M, Xenarios I, Von Laer D, et al. Type I interferons protect T cells against NK cell attack mediated by the activating receptor NCR1. Immunity. (2014) 40:961-73. doi: 10.1016/j. immuni.2014.05.003

177. Yuen M-F, Schiefke I, Yoon J, Ahn SH, Heo J, Kim JH, et al. RNAinterference therapy with $\mathrm{ARC}-520$ results in prolonged $\mathrm{HBs}$ Ag response in patients with chronic hepatitis B infection. Hepatology. (2019) 177:he31008. doi: 10.1002/ hep. 31008

178. Fanning GC, Zoulim F, Hou J, Bertoletti A. Therapeutic strategies for hepatitis B virus infection: towards a cure. Nat Rev Drug Discov. (2019) 18:827-44. doi: 10.1038/s41573-019-0037-0

179. Yuen M-F, Agarwal K, Gane EJ, Schwabe C, Ahn SH, Kim DJ, et al. Safety, pharmacokinetics, and antiviral effects of ABI-H0731, a hepatitis $\mathrm{B}$ virus core inhibitor: a randomised, placebo-controlled phase 1 trial. Lancet Gastroenterol Hepatol. (2020) 5:152-66. doi: 10.1016/S2468-1253(19) 30346-2

180. Bazinet M, Pantea V, Placinta G, Moscalu I, Cebotarescu V, Cojuhari L, et al. Establishment of high rates of functional cure of HBeAg negative chronic HBV infection with REP 2139-Mg based combination therapy: ongoing follow-up results from the REP 401 study. J Hepatol. (2019) 70:e486.

181. Gehring AJ, Xue S-A, Ho ZZ, Teoh D, Ruedl C, Chia A, et al. Engineering virus-specific $\mathrm{T}$ cells that target $\mathrm{HBV}$ infected hepatocytes and hepatocellular carcinoma cell lines. J Hepatol. (2011) 55:103-10. doi: 10.1016/j.jhep.2010.10. 025

182. Qasim W, Brunetto M, Gehring AJ, Xue S-A, Schurich A, Khakpoor A, et al. Immunotherapy of HCC metastases with autologous T cell receptor redirected T cells, targeting HBsAg in a liver transplant patient. J Hepatol. (2015) 62:486-91. doi: 10.1016/j.jhep.2014.10.001

183. Krebs K, Böttinger N, Huang L, Chmielewski M, Arzberger S, Gasteiger G, et al. $\mathrm{T}$ cells expressing a chimeric antigen receptor that binds hepatitis $\mathrm{B}$ virus envelope proteins control virus replication in mice. Gastroenterology. (2013) 145:456-65. doi: 10.1053/j.gastro.2013.04.047

184. Festag MM, Festag J, Fräßle SP, Asen T, Sacherl J, Schreiber S, et al. Evaluation of a fully human, hepatitis B virus-specific chimeric antigen receptor in an immunocompetent mouse model. Mol Ther. (2019) 27:947-59. doi: 10.1016/ j.ymthe.2019.02.001

185. Kah J, Koh S, Volz T, Ceccarello E, Allweiss L, Lütgehetmann M, et al. Lymphocytes transiently expressing virus-specific $\mathrm{T}$ cell receptors reduce hepatitis B virus infection. J Clin Invest. (2017) 127:3177-88. doi: 10.1172/ JCI93024

186. Cherkassky L, Morello A, Villena-Vargas J, Feng Y, Dimitrov DS, Jones DR, et al. Human CAR T cells with cell-intrinsic PD-1 checkpoint blockade resist tumor-mediated inhibition. J Clin Invest. (2016) 126:3130-44. doi: 10.1172/ JCI83092

187. Otano I, Escors D, Schurich A, Singh H, Robertson F, Davidson BR, et al. Molecular recalibration of PD-1+ antigen-specific T cells from blood and liver. Mol Ther. (2018) 26:2553-66. doi: 10.1016/j.ymthe.2018.08.013

188. Abate-Daga D, Hanada K, Davis JL, Yang JC, Rosenberg SA, Morgan RA. Expression profiling of TCR-engineered T cells demonstrates overexpression of multiple inhibitory receptors in persisting lymphocytes. Blood. (2013) 122:1399-410. doi: 10.1182/blood-2013-04-495531

189. Lynn RC, Weber EW, Sotillo E, Gennert D, Xu P, Good Z, et al. c-Jun overexpression in CAR T cells induces exhaustion resistance. Nature. (2019) 576:293-300. doi: 10.1038/s41586-019-1805-z

190. Peppa D, Micco L, Javaid A, Kennedy PTF, Schurich A, Dunn C, et al Blockade of immunosuppressive cytokines restores NK cell antiviral function in chronic hepatitis B virus infection. PLoS Pathog. (2010) 6:e1001227. doi: 10.1371/journal.ppat.1001227

191. Lampertico P, Agarwal K, Berg T, Buti M, Janssen HLA, Papatheodoridis G, et al. 2017 clinical practice guidelines on the management of hepatitis B virus infection. J Hepatol. (2017) 67:370-98. doi: 10.1016/j.jhep.2017.03.021

192. Fisicaro P, Barili V, Acerbi G, Montanini B, Laccabue D, Guerrieri F, et al. Proteasome dysfunction as a reversible defect underlying virus-specific CD8 cell exhaustion in chronic hepatitis B. J Hepatol. (2017) 66:S30. doi: 10.1016/ s0168-8278(17)30324-0

Conflict of Interest: The authors declare that the research was conducted in the absence of any commercial or financial relationships that could be construed as a potential conflict of interest.

Copyright (C) 2020 Fisicaro, Barili, Rossi, Montali, Vecchi, Acerbi, Laccabue, Zecca, Penna, Missale, Ferrari and Boni. This is an open-access article distributed under the terms of the Creative Commons Attribution License (CC BY). The use, distribution or reproduction in other forums is permitted, provided the original author(s) and the copyright owner(s) are credited and that the original publication in this journal is cited, in accordance with accepted academic practice. No use, distribution or reproduction is permitted which does not comply with these terms. 